Review Article

\title{
Dynamic Analysis of Functionally Graded Porous Plates Resting on Elastic Foundation Taking into Mass subjected to Moving Loads Using an Edge-Based Smoothed Finite Element Method
}

\author{
Trung Thanh Tran, ${ }^{1}$ Quoc-Hoa Pham $\mathbb{D}^{2,3}$ and Trung Nguyen-Thoi ${ }^{2,3}$ \\ ${ }^{1}$ Department of Mechanics, Le Quy Don Technical University, Hanoi, Vietnam \\ ${ }^{2}$ Division of Computational Mathematics and Engineering, Institute for Computational Science, Ton Duc Thang University, \\ Ho Chi Minh City, Vietnam \\ ${ }^{3}$ Faculty of Civil Engineering, Ton Duc Thang University, Ho Chi Minh City, Vietnam
}

Correspondence should be addressed to Quoc-Hoa Pham; phamquochoa@tdtu.edu.vn

Received 2 March 2020; Revised 20 July 2020; Accepted 24 July 2020; Published 18 August 2020

Academic Editor: Marco Gherlone

Copyright (C) 2020 Trung Thanh Tran et al. This is an open access article distributed under the Creative Commons Attribution License, which permits unrestricted use, distribution, and reproduction in any medium, provided the original work is properly cited.

\begin{abstract}
The paper presents the extension of an edge-based smoothed finite element method using three-node triangular elements for dynamic analysis of the functionally graded porous (FGP) plates subjected to moving loads resting on the elastic foundation taking into mass (EFTIM). In this study, the edge-based smoothed technique is integrated with the mixed interpolation of the tensorial component technique for the three-node triangular element (MITC3) to give so-called ES-MITC3, which helps improve significantly the accuracy for the standard MITC3 element. The EFTIM model is formed by adding a mass parameter of foundation into the Winkler-Pasternak foundation model. Two parameters of the FGP materials, the power-law index $(k)$ and the maximum porosity distributions $(\Omega)$, take forms of cosine functions. Some numerical results of the proposed method are compared with those of published works to verify the accuracy and reliability. Furthermore, the effects of geometric parameters and materials on forced vibration of the FGP plates resting on the EFTIM are also studied in detail.
\end{abstract}

\section{Introduction}

The dynamic responses of the plates resting on the elastic foundation $(\mathrm{EF})$ subjected to moving loads have been widely investigated by many scientists around the world. The results of these works may be applied for computation in many civil engineering problems such as vehicles running on roads and airplanes moving on runways. When investigating the response of structures on the EF, authors have mainly used the oneparameter Winkler model [1] or the two-parameter Winkler-Pasternak model [2]. For example, Xiang et al. [3] used an analytical method (AM) to study the free vibration of plates. Omurtag et al. [4] analyzed the free vibration of thin plates using the finite element method (FEM). Zhou et al. [5] used the Ritz method to consider the free vibration of rectangular plates. Ferreira et al. [6] studied the free vibration of the plates by radial basis functions. Duc et al. [7] studied the nonlinear thermal dynamic response of the shear deformable functionally graded (FG) plates. Mahmoudi et al. [8] developed a refined quasi-three-dimensional shear deformation theory for analyzing FG sandwich plates under thermomechanical load. Recently, Tran et al. [9] also investigated the free vibration of the FGP plates resting on the EFTIM.

Regarding the analysis of structures subjected to moving loads, some typical works can be mentioned here as follows. $\mathrm{Wu}$ et al. [10] studied the dynamic responses of nonuniform rectangular plates with various boundary conditions (BC) using the classical plate theory (CPT) and the FEM. Frýba [11] summarized the variety of problems about the dynamic response of the plates. Taheri and Ting [12] used Green's functions to investigate the dynamic responses of plates with different boundary conditions. Hoang et al. [13] used the FEM to analyze dynamic responses of triple-layer composite plates with layers connected by shear connectors. Song et al. 
[14] considered dynamic responses of rectangular thin plates of arbitrary boundary conditions. Expanding the above studies for plates on the EF under moving loads, Zaman et al. [15] used the FEM based on the first-order shear deformation theory (FSDT) to analyze the airport pavements subjected to moving aircraft loads. In their work, the airport pavement and underlying soil medium were modeled as the thick plate, and a series of discrete linear springs and dashpots were acting at nodal points, respectively. Kim and Roesset [16] considered the dynamic responses of the plate resting on the EF under constant and harmonic moving loads. In their study, the double and triple Fourier transformations were used to approximate the moving loads, and the influences of the velocity parameters, load parameters, and the internal damping on the displacement were also examined. Huang and Thambiratnam $[17,18]$ investigated the dynamic responses of plates on the EF using the finite strip method (FSM). Seong-Min and McCullough [19] surveyed the dynamic responses for the plates resting on a viscous Winkler foundation. The influences of the varying amplitudes and a constant velocity on dynamic responses of the plates were considered in this paper. Also, Tran et al. [20] used the FSDT and FEM to study the dynamic responses of the sandwich composite plates with auxetic honeycomb core resting on the EF subjected to moving oscillator loads.

In a different aspect regarding the properties of materials, porosity can be appeared in the FG materials during the manufacturing process or intentionally created. Fundamentally, porosity reduces the stiffness of the structure; however, with excellent engineering properties like lightweight, good energy-absorbing capability, and strong thermal resistant properties, the FG porous (FGP) materials have still attracted the attention of many researchers. For example, Kim et al. [21] used an analytical method based on the modified couples stress to analyze the bending, free vibration, and buckling of the FGP microplates. Also, Coskun et al. [22] used a general third-order shear deformation theory (TSDT) to investigate the static, free vibration, and buckling of the FGP microplates. Rezaei and Saidi $[23,24]$ used an analytical method to study the free vibration of the rectangular and porous-cellular plates. Zhao et al. $[25,26]$ examined the free vibration and the dynamic responses of the FGP shallow shells by using an improved Fourier method. Regarding nonlinear problems, Li et al. [27] analyzed the nonlinear free vibration and dynamic buckling of the sandwich FGP plates with graphene platelet reinforcement (GPL) on the EF. Sahmani et al. [28] used the nonlocal theory to analyze the nonlinear large-amplitude vibrations of the FGP micro-/nanoplates with GPL reinforcement. Wu et al. [29] studied the dynamic of the FGP structures by using the FEM. In addition, Barati and Zenkour [30] used the FSDT and Galerkin's method to analyze the free vibration of the FGP cylindrical shells reinforced by the GPL. Zenkour and Barati [31] considered the electro-thermoelastic free vibration of the FGP plates integrated with piezoelectric layers using an analytical method. Daikh and Zenkour [32] calculated the free vibration of the FG sandwich plates. Sobhy and Zenkour [33] considered the effects of the porosity distribution on the free vibration of the FG nanoplate using quasi-3D refined theory. Nguyen et al. developed the polygonal finite element method
(PFEM) combined with HSDT to calculate the free vibration of FGP plates reinforced by the GPL [34] and active-controlled vibration of the FGP plate reinforced by the GPL [35]. Moreover, Tran et al. [36] investigated the free vibration of the FGP variable-thickness plates using an edge-based smoothed finite element method (ES-FEM). Lurlaro et al. [37] used the refine zigzag theory to analyze the free vibration of FG sandwich plates.

In another aspect regarding the development of numerical methods, the original MITC3 element [38] was integrated with an edge-based smoothed finite element method (ES-FEM) [39-44] to give so-called ES-MITC3 [45] for analysis of different structures. For example, Chau-Dinh et al. [45] proposed ES-MITC3 to study the free vibration for the isotropic plates. Nguyen et al. [46] extended ES-MITC3 to analyze the free vibration of the FG plates based on the TSDT. Pham et al. [9, 47-50] developed ES-MITC3 to investigate the static and vibration of structures. The numerical results in these works have almost shown that ES-MITC3 has the following advantageous properties: (1) ES-MITC3 can avoid the shear locking phenomenon even with the ratio of the thickness to the length of the structures reaching $10^{-8}$; (2) ES-MITC3 has better accuracy than some available triangular elements in the literature such as MITC3 [38], DSG3 [51], and CS-DSG3 [52] and is a good competitor with the quadrilateral element MITC4 [53].

Based on the aforementioned literature review, the objective of this work is to further extend the ES-MITC3 element for investigating the dynamic responses of the FGP plates resting on the EFTIM subjected to moving loads. In this study, the forced vibration equation is based on the FSDT due to simplicity and high computational efficiency (which means that it can ensure a high accuracy with a lower computational cost). The accuracy and reliability of the proposed method are performed by comparing the present numerical results with those of other published works in the literature. Furthermore, the influences of geometric parameters, material properties, and loads on the dynamic responses of the FGP plates subjected to the moving loads are also examined in detail.

\section{Functionally Graded Porous Plates on the EF}

Consider an FGP plate resting on the EFTIM subjected to a moving load as shown in Figure 1.

The FGP materials with the variation of two parameters and three distribution cases of porosity along with thickness are expressed as follows [21, 22]:

$$
\begin{aligned}
& \text { case 1: } \Lambda(z)=\Omega \cos \left(\frac{\pi z}{h}\right), \\
& \text { case 2: } \Lambda(z)=\Omega \cos \left[\frac{\pi}{2}\left(\frac{z}{h}+0.5\right)\right], \\
& \text { case 3: } \Lambda(z)=\Omega \cos \left[\frac{\pi}{2}\left(\frac{z}{h}-0.5\right)\right],
\end{aligned}
$$

where $\Omega$ is the maximum porosity distribution value. The property of the FGP materials is obtained by formulation: 


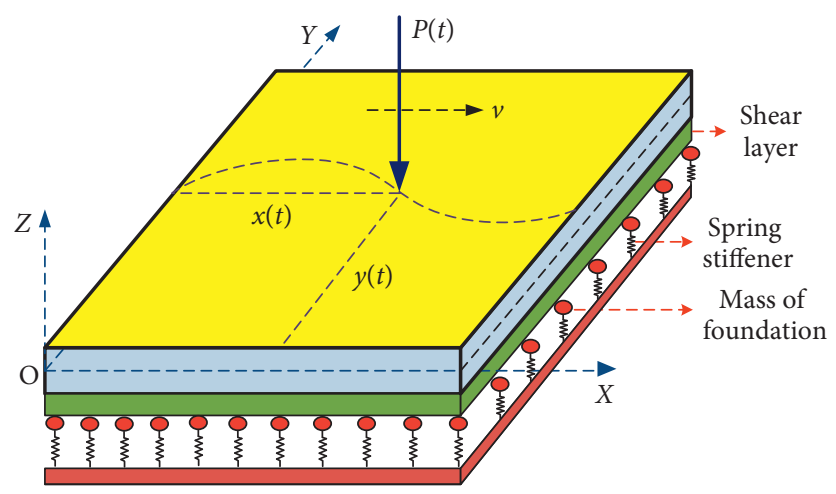

FIgUre 1: The FGP plate resting on the EFTIM subjected to a moving load.

$$
P(z)=\left[\left(P_{\mathrm{t}}-P_{\mathrm{b}}\right)\left(\frac{z}{h}+0.5\right)^{k}+P_{\mathrm{b}}\right](1-\Lambda(z)),
$$

where $P_{\mathrm{t}}$ and $P_{\mathrm{b}}$ are the typical material properties at the top and the bottom surfaces, respectively, and $k$ is the power-law index. The distributions of porosity through thickness of the plate are shown in Figure 2(a). The porosity distribution of case 1 is symmetric corresponding to the midplane-enhanced distribution, and those of case 2 and case 3 are bottom- and top surface-enhanced distributions, respectively. In addition, Figures 2(b)-2(d) show the distributions of the normalized typical property associated with three different cases of the porosity distributions with parameters $\Omega=0.5, k=0,1,5$, and $P_{t} / P_{b}=10$.

The EFTIM model is built based on the Winkler-Pasternak foundation by adding a mass parameter of the foundation:

$$
\mathbf{q}_{e}=k_{1} w(x, y, t)-k_{2}\left(\frac{\partial^{2}}{\partial x^{2}}+\frac{\partial^{2}}{\partial y^{2}}\right) w(x, y, t)+m_{\mathrm{f}} \frac{\partial^{2} w(x, y, t)}{\partial t^{2}},
$$

where $w$ is the vertical displacement of the FGP plate; $k_{1}$ and $k_{2}$ are the Winkler foundation stiffness and shear layer stiffness of the Pasternak foundation, respectively; $m_{\mathrm{f}}=\beta \mu_{\mathrm{F}} \rho$ in which the parameter $\beta\left(\mathrm{kg}^{-1}\right)$ is the influence level of the foundation mass on the free vibration response of the structures, which is determined by experiments; and $\mu_{\mathrm{F}}$ is the density ratio of the foundation to the plate material $\left(\rho_{\mathrm{F}} / \rho\right)$. From equation (3), it can be seen that the investigation of the EFTIM model and Winkler-Pasternak foundation model on the static analysis is similar. However, these two models become complex in the dynamic response problems. If the influence of the foundation mass parameter is ignored, the EFTIM model will be equivalent to the Winkler-Pasternak foundation model, and hence, the EFTIM model will be close to the EF model in practice.

\section{The First-Order Shear Deformation Theory and Weak Form for FGP Plates}

3.1. The First-Order Shear Deformation Theory for the FGP Plates. The displacement at any point of the FGP plates in the present work based on the FSDT model can be expressed as

$$
\left\{\begin{array}{l}
u(x, y, z)=u_{0}(x, y)+z \theta_{x}(x, y), \\
v(x, y, z)=v_{0}(x, y)+z \theta_{y}(x, y), \\
w(x, y, z)=w_{0}(x, y),
\end{array}\right.
$$

where $u, v, w, \theta_{x}$, and $\theta_{y}$ are five unknown displacements of the midsurface of the plate, and the bending strain field of the plate can be expressed as

$$
\boldsymbol{\varepsilon}=\boldsymbol{\varepsilon}_{\mathrm{m}}+z \boldsymbol{\kappa},
$$

in which the membrane strain is defined as

$$
\boldsymbol{\varepsilon}_{\mathrm{m}}=\left\{\begin{array}{c}
u_{0, x} \\
v_{0, y} \\
u_{0, y}+v_{0, x}
\end{array}\right\} .
$$

The bending strain is defined as

$$
\mathbf{\kappa}=\left\{\begin{array}{c}
\theta_{x, x} \\
\theta_{y, y} \\
\theta_{x, y}+\theta_{y, x}
\end{array}\right\},
$$

and the transverse shear strain is defined as

$$
\gamma=\left\{\begin{array}{c}
w_{0, x}+\theta_{x} \\
w_{0, y}+\theta_{y}
\end{array}\right\}
$$

From Hooke's law, the linear stress-strain relations of the FGP plates can be expressed as

$$
\left\{\begin{array}{c}
\sigma_{x} \\
\sigma_{y} \\
\tau_{x y} \\
\tau_{x z} \\
\tau_{y z}
\end{array}\right\}=\left[\begin{array}{ccccc}
Q_{11} & Q_{12} & 0 & 0 & 0 \\
Q_{21} & Q_{22} & 0 & 0 & 0 \\
0 & 0 & Q_{66} & 0 & 0 \\
0 & 0 & 0 & Q_{55} & 0 \\
0 & 0 & 0 & 0 & Q_{44}
\end{array}\right]\left\{\begin{array}{c}
\boldsymbol{\varepsilon}_{x} \\
\boldsymbol{\varepsilon}_{y} \\
\gamma_{x y} \\
\gamma_{x z} \\
\gamma_{y z}
\end{array}\right\},
$$

where 


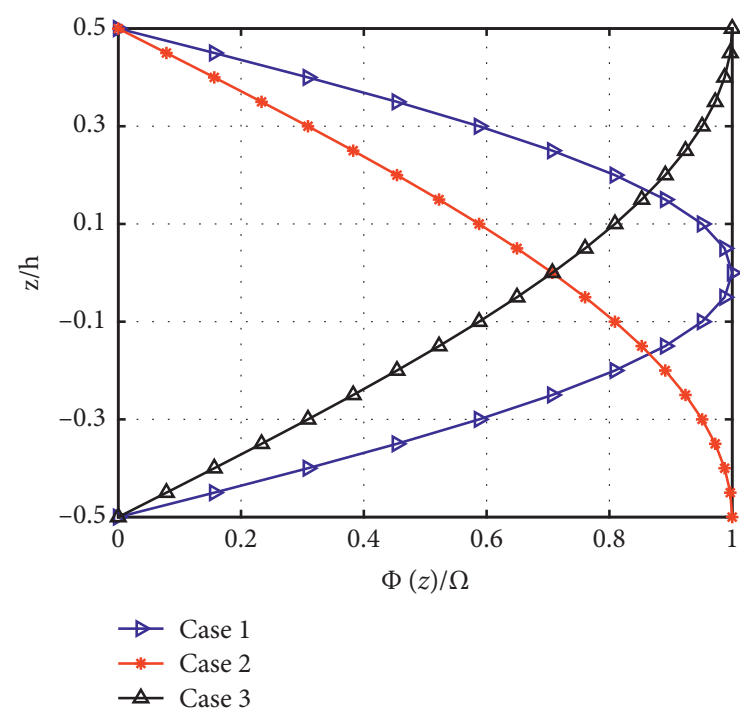

(a)

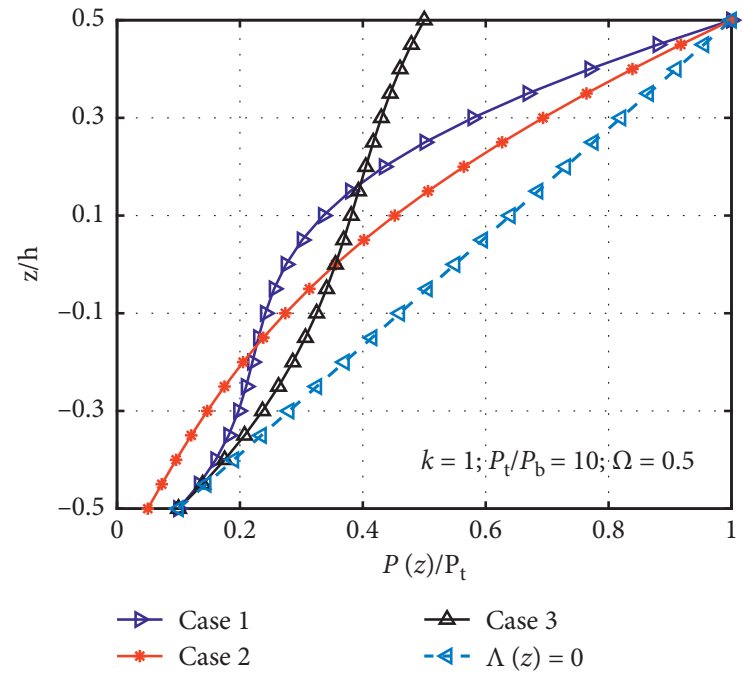

(c)

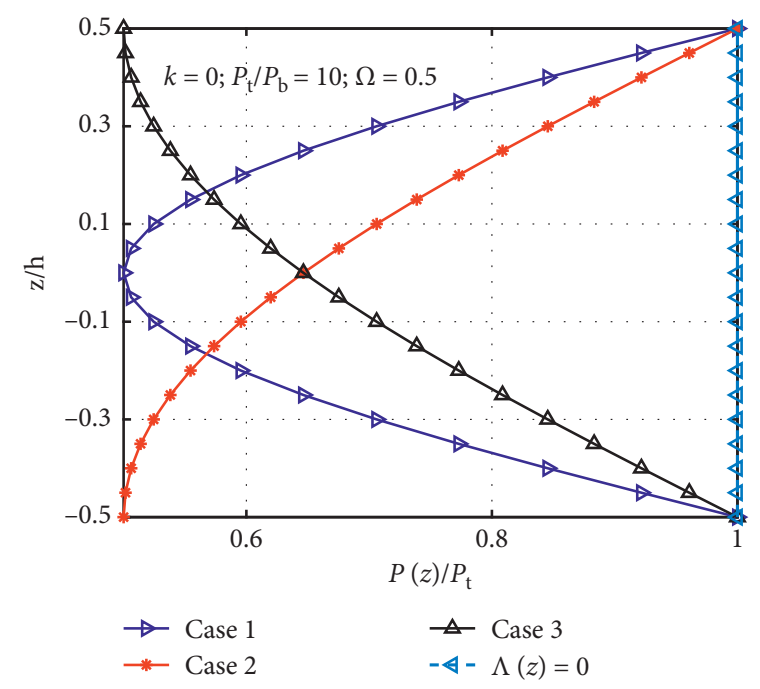

(b)

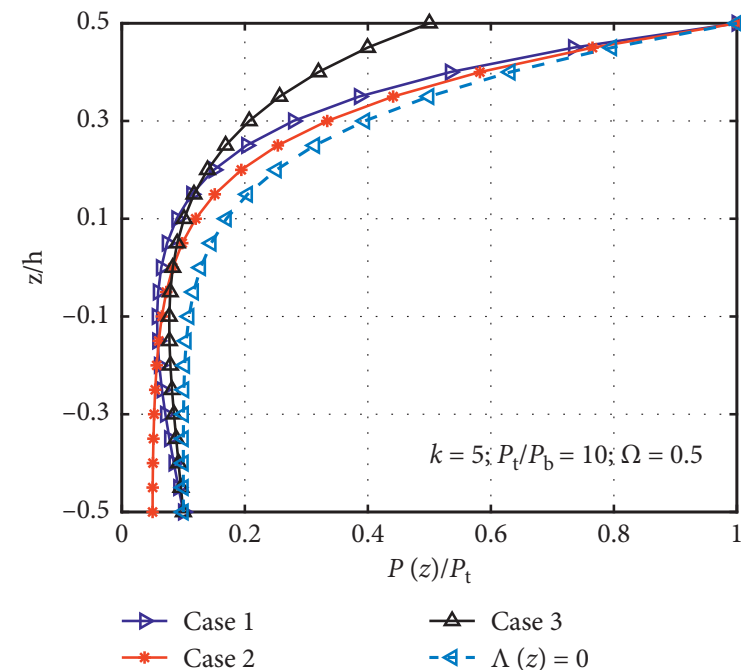

(d)

Figure 2: Distribution of porosity and typical material property. (a) Distribution of porosity along the $z$-axis. (b) Distribution material property with $k=0$. (c) Distribution material property with $k=1$. (d) Distribution material property with $k=5$.

$$
\begin{aligned}
& Q_{11}=Q_{22}=\frac{E(z)}{1-v^{2}} ; \\
& Q_{12}=Q_{21}=\frac{v E(z)}{1-v^{2}} \\
& Q_{44}=Q_{55}=Q_{66}=\frac{E(z)}{2(1+v)}
\end{aligned}
$$

in which $E(z)$ is effective Young's modulus calculated by equation (2), and $v$ is Poisson's ratio.

3.2. Weak Form Equations. To obtain the equations of the motion of the FGP plate for the dynamic analysis, Hamilton's principle is applied with the following form:

$$
\int_{t_{1}}^{t_{2}}(\delta u+\delta v-\delta k) \mathrm{d} t=0
$$

where $u, k$, and $v$ are the strain energy, the kinetic energy, and the work done by applied forces, respectively.

The strain energy is expressed as

$$
u=u^{p}+u^{f}
$$

where the strain energy of the foundation is computed by

$$
u^{f}=\frac{1}{2} \int_{\Psi}\left(k_{1} w^{2}-k_{2}\left[\left(\frac{\partial^{2} w}{\partial x^{2}}\right)^{2}+\left(\frac{\partial^{2} w}{\partial y^{2}}\right)^{2}\right]\right) \mathrm{d} \Psi
$$

and the strain energy of the FGP plate is computed by

$$
u^{p}=\frac{1}{2} \int_{\Psi}\left(\boldsymbol{\varepsilon}^{T} \mathbf{D} \boldsymbol{\varepsilon}+\boldsymbol{\gamma}^{T} \mathbf{S} \boldsymbol{\gamma}\right) \mathrm{d} \Psi,
$$

in which 


$$
\begin{aligned}
\boldsymbol{\varepsilon} & =\left[\begin{array}{ll}
\boldsymbol{\varepsilon}_{\mathrm{m}} & \boldsymbol{\kappa}
\end{array}\right]^{T}, \\
\mathbf{D} & =\left[\begin{array}{ll}
\mathbf{A} & \mathbf{B} \\
\mathbf{B} & \mathbf{H}
\end{array}\right] .
\end{aligned}
$$

And $\mathbf{A}, \mathbf{B}, \mathbf{H}$, and $\mathbf{S}$ are given by

$$
\begin{aligned}
(\mathbf{A}, \mathbf{B}, \mathbf{H}) & =\int_{-h(x, y) / 2}^{h(x, y) / 2}\left(1, z, z^{2}\right)\left[\begin{array}{ccc}
Q_{11} & Q_{12} & 0 \\
Q_{21} & Q_{22} & 0 \\
0 & 0 & Q_{66}
\end{array}\right], \\
\mathbf{S} & =\int_{-h(x, y) / 2}^{h(x, y) / 2}\left[\begin{array}{cc}
Q_{55} & 0 \\
0 & Q_{44}
\end{array}\right] \mathrm{d} z .
\end{aligned}
$$

The kinetic energy is defined as

$$
k=k^{p}+k^{f},
$$

where the kinetic energy of the FGP plate is computed by

$$
k^{p}=\frac{1}{2} \int_{\Psi} \dot{u}^{T} \mathbf{m}_{p} \dot{u} \mathrm{~d} \Psi,
$$

in which $\mathbf{u}^{T}=\left[\begin{array}{lllllll}u_{0} & v_{0} & w_{0} & \theta_{x} & \theta_{y} & \phi_{x} & \phi_{y}\end{array}\right]$, and $\mathbf{m}_{\mathrm{p}}$ is the mass matrix which is defined as follows:

$$
\mathbf{m}_{\mathrm{p}}=\left[\begin{array}{ccccc}
I_{1} & 0 & 0 & 0 & 0 \\
0 & I_{1} & 0 & 0 & I_{2} \\
0 & 0 & I_{1} & 0 & 0 \\
0 & 0 & 0 & I_{3} & 0 \\
0 & 0 & 0 & 0 & I_{3}
\end{array}\right],
$$

with $\left(I_{1}, I_{2}, I_{3}\right)=\int_{-h(x, y) / 2}^{h(x, y) / 2} \rho\left(1, z, z^{2}\right) \mathrm{d} z$.

The kinetic energy of the mass of the foundation is defined as

$$
k^{f}=\frac{1}{2} \int_{\Psi} \dot{\mathbf{w}}^{T} m_{\mathrm{f}} \dot{\mathbf{w}} \mathrm{d} \Psi .
$$

The work done by applied forces is given by

$$
V=\int_{\Psi} q \mathbf{w}^{T} \mathrm{~d} \Psi .
$$

Substituting equations (14) and (17) into equation (11), the weak-form formulation for the dynamic analysis of FGP plates resting on the EF is finally obtained as

$$
\begin{aligned}
& \int_{\Psi} \delta \boldsymbol{\varepsilon}^{T} \mathbf{D} \boldsymbol{\varepsilon} d \Psi+\int_{\Psi} \delta \boldsymbol{\gamma}^{T} \mathbf{S} \boldsymbol{\gamma} \mathrm{d} \Psi \\
& \quad+\int_{\Psi} \delta \mathbf{w}^{T}\left[k_{1} \mathbf{w}-k_{2}\left(\frac{\partial^{2} \mathbf{w}}{\partial x^{2}}+\frac{\partial^{2} \mathbf{w}}{\partial y^{2}}\right)\right] \mathrm{d} \Psi+\int_{\Psi} q \delta \mathbf{w}^{T} \mathrm{~d} \Psi \\
& =\int_{\Psi} \dot{\mathbf{u}}^{T} \mathrm{~m}_{\mathrm{p}} \dot{u} \mathrm{~d} \Psi+\int_{\Psi} \dot{\mathbf{w}}^{T} \mathrm{~m}_{\mathrm{f}} \dot{\mathbf{w}} \mathrm{d} \Psi .
\end{aligned}
$$

\section{Formulation of the ES-MITC3 Method for FGP Plates}

4.1. Formulation of the Finite Element Using the MITC3 Element. The middle surface of plate $\psi$ is discretized into $n^{e}$ finite three-node triangular elements with $n^{n}$ nodes such that $\psi \approx \sum_{e=1}^{n^{e}} \psi_{e}$ and $\psi_{i}=\varnothing, i \neq j$. The generalized displacements at any point $\mathbf{u}^{e}=\left[u_{j}^{e}, v_{j}^{e}, w_{j}^{e}, \theta_{x j}^{e}, \theta_{y j}^{e}\right]^{T}$ for elements of the FGP plates are approximated as

$$
\mathbf{u}^{e}=\sum_{j=1}^{n^{n e}}\left[\begin{array}{ccccc}
N_{I}(\mathrm{x}) & 0 & 0 & 0 & 0 \\
0 & N_{I}(\mathrm{x}) & 0 & 0 & 0 \\
0 & 0 & N_{I}(\mathrm{x}) & 0 & 0 \\
0 & 0 & 0 & N_{I}(\mathrm{x}) & 0 \\
0 & 0 & 0 & 0 & N_{I}(\mathrm{x})
\end{array}\right] \mathbf{d}_{j}^{e}=\sum_{j=1}^{n^{n e}} \mathbf{N}(\mathrm{x}) \mathbf{d}_{j}^{e},
$$

where $n^{n e}$ is the number of nodes of the plate element and $\mathbf{N}(x)$ and $\mathbf{d}_{j}^{e}=\left[u_{j}^{e}, v_{j}^{e}, w_{j}^{e}, \theta_{x j}^{e}, \theta_{y j}^{e}\right]^{T}$ are the shape function and the nodal degrees of freedom (DOF) of $\mathbf{u}^{e}$ associated with the $j^{\text {th }}$ node of the element, respectively.

Similar to the standard triangular element, the linear membrane and the bending strains of a MITC 3 element can be expressed in matrix forms as follows:

$$
\begin{gathered}
\varepsilon_{\mathrm{m}}^{e}=\left[\begin{array}{lll}
\mathbf{B}_{\mathrm{m} 1}^{e} & \mathbf{B}_{\mathrm{m} 2}^{e} & \mathbf{B}_{\mathrm{m} 3}^{e}
\end{array}\right] \mathbf{d}^{e}=\mathbf{B}_{\mathrm{m}}^{e} \mathbf{d}^{e}, \\
\boldsymbol{\kappa}^{e}=\left[\begin{array}{lll}
\mathbf{B}_{\mathrm{b} 1}^{e} & \mathbf{B}_{\mathrm{b} 2}^{e} & \mathbf{B}_{\mathrm{b} 3}^{e}
\end{array}\right] \mathbf{d}^{e}=\mathbf{B}_{\mathrm{b}}^{e} \mathbf{d}^{e},
\end{gathered}
$$

where

$$
\mathbf{B}_{\mathrm{m} 1}^{e}=\frac{1}{2 A_{e}}\left[\begin{array}{ccccc}
b-c & 0 & 0 & 0 & 0 \\
0 & d-a & 0 & 0 & 0 \\
d-a & b-c & 0 & 0 & 0
\end{array}\right],
$$$$
\mathbf{B}_{\mathrm{m} 2}^{e}=\frac{1}{2 A_{e}}\left[\begin{array}{ccccc}
c & 0 & 0 & 0 & 0 \\
0 & -d & 0 & 0 & 0 \\
-d & c & 0 & 0 & 0
\end{array}\right],
$$$$
\mathbf{B}_{\mathrm{m} 3}^{e}=\frac{1}{2 A_{e}}\left[\begin{array}{ccccc}
-b & 0 & 0 & 0 & 0 \\
0 & -d & 0 & 0 & 0 \\
-d & c & 0 & 0 & 0
\end{array}\right],
$$$$
\mathbf{B}_{\mathrm{b} 1}^{e}=\frac{1}{2 A_{e}}\left[\begin{array}{ccccc}
0 & 0 & 0 & b-c & 0 \\
0 & 0 & 0 & 0 & d-a \\
0 & 0 & 0 & d-a & b-c
\end{array}\right],
$$

$$
\begin{aligned}
& \mathbf{B}_{\mathrm{b} 2}^{e}=\frac{1}{2 A_{e}}\left[\begin{array}{ccccc}
0 & 0 & 0 & c & 0 \\
0 & 0 & 0 & 0 & -d \\
0 & 0 & 0 & -d & c
\end{array}\right], \\
& \mathbf{B}_{\mathrm{b} 3}^{e}=\frac{1}{2 A_{e}}\left[\begin{array}{ccccc}
0 & 0 & 0 & -b & 0 \\
0 & 0 & 0 & 0 & a \\
0 & 0 & 0 & a & -b
\end{array}\right] .
\end{aligned}
$$

To avoid the shear locking problem when the thickness of the FGP plates becomes very thin, the formulation of the 
transverse shear strains of the triangular element based on the FSDT [38] in this paper is given by

$$
\gamma^{e}=\mathbf{B}_{\mathrm{s}}^{e} \mathbf{d}^{e}
$$

in which

$$
\mathbf{B}_{\mathrm{s}}^{e}=\left[\begin{array}{lll}
\mathbf{B}_{\mathrm{s} 1}^{e} & \mathbf{B}_{\mathrm{s} 2}^{e} & \mathbf{B}_{\mathrm{s} 3}^{e}
\end{array}\right]
$$

with

$$
\begin{aligned}
& \mathbf{B}_{\mathrm{s} 1}^{e}=\mathbf{J}^{-1}\left[\begin{array}{cccccc}
0 & 0 & -1 & \frac{a}{3}+\frac{d}{6} & \frac{b}{3}+\frac{c}{6} \\
0 & 0 & -1 & \frac{d}{3}+\frac{a}{6} & \frac{c}{3}+\frac{b}{6}
\end{array}\right], \\
& \mathbf{B}_{\mathrm{s} 2}^{e}=\mathbf{J}^{-1}\left[\begin{array}{ccccc}
0 & 0 & 1 & \frac{a}{3}-\frac{d}{6} & \frac{b}{3}-\frac{c}{6} \\
& & & \\
0 & 0 & 0 & \frac{d}{6} & \frac{c}{6}
\end{array}\right], \\
& \mathbf{B}_{\mathrm{s} 3}^{e(0)}=\mathbf{J}^{-1}\left[\begin{array}{lllll}
0 & 0 & 0 & \frac{a}{6} & \frac{b}{6} \\
0 & 0 & 1 & \frac{d}{2}-\frac{a}{6} & \frac{c}{2}-\frac{b}{6}
\end{array}\right],
\end{aligned}
$$

where

$$
\mathbf{J}^{-1}=\frac{1}{2 A_{e}}\left[\begin{array}{cc}
c & -b \\
-d & a
\end{array}\right]
$$

in which $a=x_{2}-x_{1}, b=y_{2}-y_{1}, c=y_{3}-y_{1}$, and $d=x_{3}-$ $x_{1}$ are pointed out in Figure 3 , and $A_{e}$ is the area of the threenode triangular element.

Substituting the discrete displacement fields into equation (22), we obtained the discrete system equations for the dynamic response analysis of the FGP plates resting on the $\mathrm{EF}$, respectively, as

$$
\mathbf{M} \ddot{\mathbf{d}}+\mathbf{K} \mathbf{d}=\mathbf{F}(t),
$$

where $\mathbf{K}$ is the stiffness matrix of the FGP plates resting on the EF and $\mathbf{M}$ is the mass matrix, and they are assembled by

$$
\begin{aligned}
\mathbf{K} & =\sum_{e=1}^{n^{e}}\left(\mathbf{K}_{\mathrm{p}}^{e}+\mathbf{K}_{\mathrm{f}}^{e}\right), \\
\mathbf{M} & =\sum_{e=1}^{n^{e}}\left(\mathbf{M}_{\mathrm{p}}^{e}+\mathbf{M}_{\mathrm{f}}^{e}\right), \\
\mathbf{F}(t) & =\sum_{e=1}^{n^{e}} \mathbf{F}^{e}(t),
\end{aligned}
$$

where $\mathbf{K}_{\mathrm{p}}^{e}$ is the element stiffness matrix of the plates and is computed by

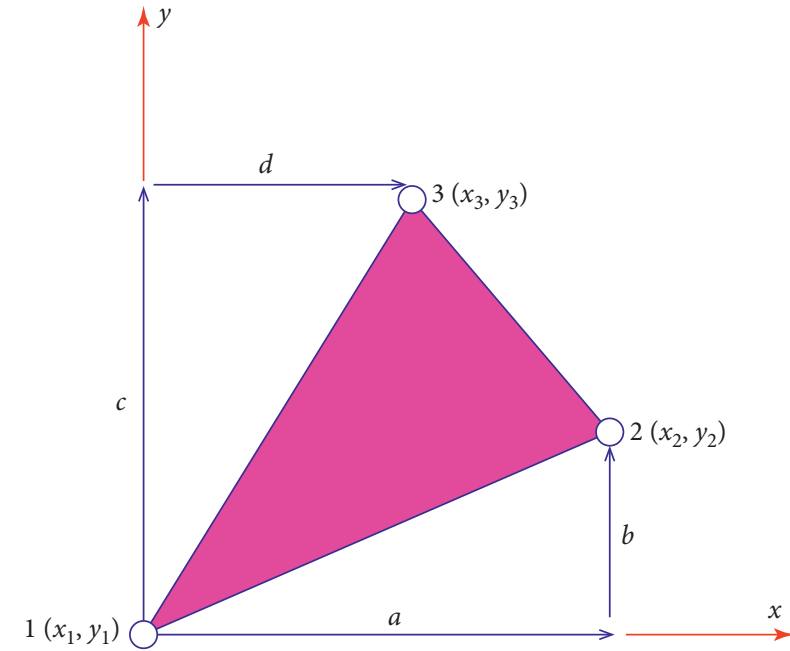

Figure 3: Three-node triangular element in the local coordinates.

$$
\mathbf{K}_{\mathrm{p}}^{e}=\int_{\psi_{e}} \mathbf{B}^{T} \mathbf{D B} \mathrm{d} \psi_{e}+\int_{\psi_{e}} \mathbf{B}_{S}^{T} \mathbf{S} \mathbf{B}_{S} \mathrm{~d} \psi_{e},
$$

in which

$$
\mathbf{B}^{e}=\left[\begin{array}{ll}
\mathbf{B}_{m}^{e} & \mathbf{B}_{b}^{e}
\end{array}\right]
$$

and $\mathbf{K}_{f}^{e}$ is the element stiffness matrix of the EF and is computed by

$$
\begin{aligned}
\mathbf{K}_{f}^{e}= & k_{1} \int_{\psi_{e}} \mathbf{N}_{w}^{T} \mathbf{N}_{w} \mathrm{~d} \psi_{e}+k_{2} \int_{\psi_{e}} \\
& {\left[\left(\frac{\partial \mathbf{N}_{w}}{\partial \mathrm{x}}\right)^{T}\left(\frac{\partial \mathbf{N}_{w}}{\partial \mathrm{x}}\right)+\left(\frac{\partial \mathbf{N}_{w}}{\partial \mathrm{y}}\right)^{T}\left(\frac{\partial \mathbf{N}_{w}}{\partial \mathrm{y}}\right)\right] \mathrm{d} \psi_{e} }
\end{aligned}
$$

with

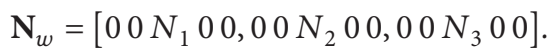

The mass matrix of the plate is given by

$$
\mathbf{M}_{\mathrm{p}}^{e}=\int_{\psi_{e}} \mathbf{N}^{T} \mathbf{m}_{\mathrm{p}} \mathbf{N d} \psi_{e}
$$

where $\mathbf{M}_{f}^{e}$ is the element mass matrix of the EF and is computed by

$$
\mathbf{M}_{\mathrm{f}}^{e}=\mathbf{m}_{\mathrm{f}} \int_{\psi_{e}} \mathbf{N}_{w}^{T} \mathbf{N}_{w} \mathrm{~d} \psi_{e}
$$

In this work, we consider the moving loads depending on the time $P(t)$. This load moves via the direction perpendicular of the FGP plates corresponding to the variable velocity $v$ as shown in Figure 1 . The equivalent distributed force is a function of the moving load at the position $(x=$ $\xi ; y=\eta)$ and the Dirac delta function [11]:

$$
q(x, y, t)=P(t) \cdot \delta(x-\xi)(y-\eta) .
$$

The nodal force vector of the element is computed from the distributed force $q(x, y, t)$ applying on the element as follows: 


$$
\mathbf{F}^{e}(t)=\int_{\psi_{e}} q(x, y, t) \mathbf{N}_{w}^{T} \mathrm{~d} \psi_{e}=\int_{\psi_{e}} P(t) \cdot \delta(x-\xi)(y-\eta) \mathbf{N}_{w}^{T} \mathrm{~d} \psi_{e} .
$$

In the case of taking into account the structural damping, we have the force vibration equation of the plate given by

$$
\mathbf{M} \ddot{\mathbf{d}}+\mathbf{C} \dot{\mathbf{d}}+\mathbf{K} \mathbf{d}=\mathbf{F}(t),
$$

in which $\mathbf{C}=\alpha \mathbf{M}+\beta \mathbf{K}$ and $\alpha$ and $\beta$ are Rayleigh drag coefficients [11].

Equation (41) includes the linear differential equation with coefficients depending on time. In order to solve the system of equations, we use the Newmark-beta method [11] with the flowchart given in [54].

\subsection{Formulation of an ES-MITC3 Method for the FGP Plates.} In the ES-MITC3 formulation, the computation of the local stiffness matrix is no longer based on the element domain but on the smoothing domain, in which the smoothing domain $\psi^{k}$ is constructed based on the edges of the triangular elements such that $\psi=\cup_{k=1}^{n^{k}} \psi^{k}$ and $\psi_{i}^{k} \cap \psi_{j}^{k}=\varnothing$ for $i \neq j$ An edge-based smoothing domain $\psi^{k}$ associated with the inner edge $k$ is formed by connecting two end-nodes of the edge to the centroids of adjacent triangular elements, as shown in Figure 4.

Then, by using the edge-based smoothed technique of the ES-FEM [46], the smoothed membrane, bending strains $\widetilde{\kappa}^{k}, \widetilde{\boldsymbol{\varepsilon}}_{\mathrm{m}}^{k}$, and the smoothed shear strain $\widetilde{\gamma}^{k}$ over the smoothing domain $\psi^{k}$ are computed by

$$
\begin{gathered}
\widetilde{\varepsilon}_{\mathrm{m}}^{k}=\int_{\psi^{k}} \boldsymbol{\varepsilon}_{\mathrm{m}} \Phi^{k}(\mathbf{x}) \mathrm{d} \psi, \\
\widetilde{\mathbf{\kappa}}^{k}=\int_{\psi^{k}} \boldsymbol{\kappa} \Phi^{k}(\mathbf{x}) \mathrm{d} \psi, \\
\tilde{\boldsymbol{\gamma}}^{k}=\int_{\psi^{k}} \boldsymbol{\gamma} \Phi^{k}(\mathrm{x}) \mathrm{d} \psi,
\end{gathered}
$$

where $\boldsymbol{\varepsilon}_{\mathrm{m}}, \kappa$, and $\gamma$ are the compatible membrane, bending strain, and the transverse shear strain, respectively, of the MITC3 triangular elements given in equations (5) and (8) and $\Phi^{k}(x)$ is a smoothing function that satisfies at least the unity property $\int_{\psi^{k}} \Phi^{k}(\mathbf{x}) \mathrm{d} \psi=1$.

In the present work, we use the constant smoothing function:

$$
\Phi^{k}(\mathbf{x})= \begin{cases}\frac{1}{A^{k}}, & \mathbf{x} \in \psi^{k}, \\ 0, & \mathbf{x} \notin \psi^{k},\end{cases}
$$

in which $A^{k}$ is the area of the smoothing domain $\psi^{k}$ and is defined by

$$
A^{k}=\int_{\psi^{k}} \mathrm{~d} \psi=\frac{1}{3} \sum_{i=1}^{n^{e k}} A^{i}
$$

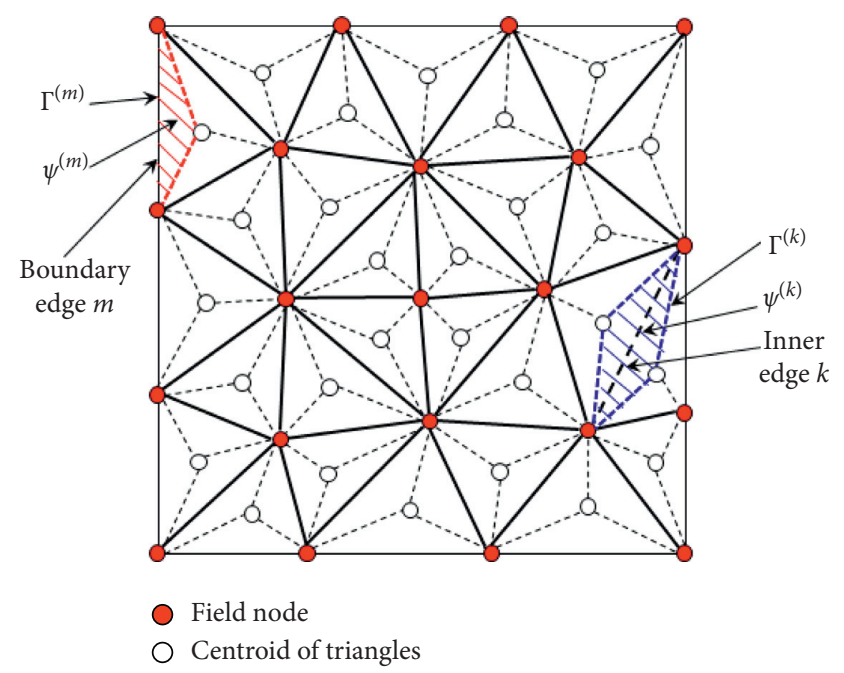

FIGURE 4: The edge-based smoothing domain $\psi^{k}$ is constructed from triangular elements.

where $n^{e k}$ is the number of the adjacent triangular elements in the smoothing domain $\psi^{k}$ and $A^{i}$ is the area of the $i$ th triangular element attached to the edge $k$.

By substituting equations (42), (43), and (44) into equations (24), (25), and (27), the approximation of the smoothed strains on the smoothing domain $\psi^{k}$ can be expressed as

$$
\begin{aligned}
\widetilde{\varepsilon}_{m}^{k} & =\sum_{j=1}^{n^{n k}} \widetilde{\mathbf{B}}_{m j}^{k} \mathbf{d}_{j}^{k}, \\
\widetilde{\mathbf{\kappa}}^{k} & =\sum_{j=1}^{n_{s h}^{n k}} \widetilde{\mathbf{B}}_{b j}^{k} \mathbf{d}_{j}^{k}, \\
\widetilde{\boldsymbol{\gamma}} & =\sum_{j=1}^{n_{s k}^{n k}} \widetilde{\mathbf{B}}_{s j}^{k} \mathbf{d}_{j}^{k},
\end{aligned}
$$

where $n_{s h}^{n k}$ is the total number of nodes of the MITC3 triangular elements attached to edge $k\left(n_{s h}^{n k}=3\right.$ for boundary edges and $n_{s h}^{n k}=4$ for inner edges, as shown in Figure 4$) ; d_{j}^{k}$ is the nodal dof associated with the smoothing domain $\psi^{k}$; and $\widetilde{\mathbf{B}}_{m j}^{k}, \widetilde{\mathbf{B}}_{b j}^{k}$, and $\widetilde{\mathbf{B}}_{s j}^{k}$ are the smoothed membrane, bending, and shear strain gradient matrices, respectively, at the $j$ th node of the elements attached to the edge $k$ computed by

$$
\begin{gathered}
\widetilde{\mathbf{B}}_{m j}^{k}=\frac{1}{A^{k}} \sum_{i=1}^{n^{e k}} \frac{1}{3} A^{i} \mathbf{B}_{m j}^{e}, \\
\widetilde{\mathbf{B}}_{b j}^{k}=\frac{1}{A^{k}} \sum_{i=1}^{n^{e k}} \frac{1}{3} A^{i} \mathbf{B}_{b j}^{e}, \\
\widetilde{\mathbf{B}}_{s j}^{k}=\frac{1}{A^{k}} \sum_{i=1}^{n^{e k}} \frac{1}{3} A^{i} \mathbf{B}_{s j}^{e} .
\end{gathered}
$$

The stiffness matrix of the FGP plates using the ESMITC3 method is assembled by 


$$
\widetilde{\mathbf{K}}=\sum_{k=1}^{n_{s h}^{k}} \widetilde{\mathbf{K}}^{k},
$$

where $\widetilde{\mathbf{K}}^{k}$ is the ES-MITC3 stiffness matrix of the smoothing domain $\psi^{k}$ expressed by

$$
\widetilde{\mathbf{K}}^{k}=\int_{\psi^{k}}\left(\widetilde{\mathbf{B}}^{k T} \mathbf{D} \widetilde{\mathbf{B}}^{k}+\widetilde{\mathbf{B}}_{s}^{k T} \mathbf{S} \widetilde{\mathbf{B}}_{s}^{k}\right) \mathrm{d} \psi=\widetilde{\mathbf{B}}^{k T} \mathbf{D} \widetilde{\mathbf{B}}^{k} \mathbf{A}^{k}+\widetilde{\mathbf{B}}^{k T} \mathbf{S} \widetilde{\mathbf{B}}_{s}^{k} \mathbf{A}^{k}
$$

in which

$$
\widetilde{\mathbf{B}}^{k T}=\left[\begin{array}{cc}
\widetilde{\mathbf{B}}_{m j}^{k} & \widetilde{\mathbf{B}}_{b j}^{k}
\end{array}\right] .
$$

The ES-MITC3 element has some advantages such as (1) it is easy and flexible for discretizing the problem domain into three-node triangular elements, even for arbitrary complicated geometry domains; (2) it has the number of degrees of freedom similar to that of the standard triangular element or of the original MITC3 element; (3) it can avoid the shear locking phenomenon even with the ratio of the thickness to the length of the structures reaching $10^{-8}$; and (4) it has better accuracy than some available triangular elements in the literature such as MITC3 [38], DSG3 [51], CS-DSG3 [52] and is a good competitor with the quadrilateral element MITC4 [53].

\section{Accuracy Study}

To evaluate the accuracy and reliability of the proposed method in this paper, we investigate the free vibration of the plate resting on the EF without including the featured-index of the mass of the foundation $(\beta=0)$. The numerical results of the present work are compared with those of published works in the literature. For convenience, the stiffness foundation and dimensionless frequencies of plates are given by

$$
\begin{aligned}
K_{1} & =\frac{k_{1} a^{4}}{X}, \\
K_{2} & =\frac{k_{2} a^{2}}{X}, \\
\lambda & =\frac{\omega a^{2}}{\pi^{2}} \sqrt{\frac{\rho h}{X}} \text { with } X=\frac{E h^{3}}{12\left(1-v^{2}\right)} .
\end{aligned}
$$

The convergence of the first two dimensionless frequencies in the case of the fully simple support (SSSS) plate and the fully clamped (CCCC) plate with $h / a=0.1, K_{1}=$ 100 , and $K_{2}=10$ is shown in Figure 5 . It can be seen that the natural frequencies of plates under different boundary conditions using $18 \times 18$ mesh size are all converging. Table 1 shows the first three dimensionless frequencies of the plate resting on the EF in the present work, together with the available results in the literature. It can be observed that the obtained results of ES-MITC3 match well with those of the analytical solution in the published works $[5,6]$ and FEM [4]. Based on these results, the present method will use the mesh size $18 \times 18$ to analyze the dynamic response of the plates in all numerical examples of the upcoming sections.

Let us now consider an SSSS rectangular plate with length $a=10 \mathrm{~m}$, width $b=10 \mathrm{~m}$, thickness $h=0.0655 \mathrm{~m}$, modulus of elasticity $E=200 \mathrm{GPa}$, Poisson's ratio $v=0.3$, and mass density $\rho=7850 \mathrm{~kg} / \mathrm{m}^{3}$ under concentrated load $P(t)=5.1 \mathrm{kN}$ along the edge of plate $y=b / 2$ as presented in [14]. In this case, the FGP plate is considered as the isotropic plate with $E_{t}=E_{b}=E, k_{1}=k_{2}=0$, and $\beta=0$. From Figure 6 , it is observed that the deflections of the central point of the plate in the present work agree excellently with those of Song et al. [14] in both shape and magnitude.

\section{Numerical Results and Discussion}

In this section, we use the material properties of the FGP plate as presented in [21]. The moduli and mass densities of two components are presented in Table 2.

We now analyze an SSSS FGP plate for case 1 of the porosity distribution. The geometric parameters are given by $h=0.1 \mathrm{~m}, a=100 h$, and $b=a / 2$, and the material properties of the FGP plate are given as follows: the maximum porosity distribution $\Omega=0.5$, power-index $k=1$, Winkler foundation stiffness $k_{1}=50 \mathrm{kPa} / \mathrm{m}$, shear layer stiffness of the Pasternak foundation $k_{2}=5 \mathrm{kPa} \cdot \mathrm{m}$, the density ratio of the foundation $\mu_{\mathrm{F}}=0.5$, and featured-index $\beta=0.5$. The first six frequencies of the FGP plate are shown in Table 3, and the first six mode shapes are illustrated in Figure 7.

6.1. Influence of the Cases of Porosity Distributions. In this section, we examine the effects of porosity distributions on the dynamic response of the SSSS rectangular FGP plate with three different cases of porosity distributions: case 1 , case 2 , and case 3 . A moving load with magnitude $P=5 \mathrm{kN}$ moves along via the edge of the plate $y=b / 2$ with velocity $v=5 \mathrm{~m} / \mathrm{s}$. The responses of deflection, velocity, and stress $(z=0)$ at the center of the plate versus time are shown in Figures 8(a)$8(\mathrm{c})$. Figure 8(d) displays the stress at the center of the plate through thickness when the load moves to the midpoint of the plate. Maximum values of deflection, velocity, and stress at the central point of the plate are illustrated in Table 4. From these figures and Table 4, it is seen that, with the same geometrical parameter and material properties, case 1 of the porosity distribution gives the minimum value of the deflection response of the FGP plate, while case 3 of the porosity distribution gives the maximum value. In addition, it is also observed that case 1 of the porosity distribution helps reduce the oscillates better than the remaining two cases of the porosity distribution.

6.2. Influences of Velocity of Moving Loads. In this example, we consider the effects of velocity $v$ on the response of the SSSS rectangular FGP plate in case 1 of the porosity distribution. The moving load with magnitude $P=5 \mathrm{kN}$ travels along the edge of the plate $y=b / 2$ with the variation of velocity $v=5,10,15,20,25 \mathrm{~m} / \mathrm{s}$. The responses of central deflection, velocity, and stress $(z=0)$ of the plate versus time are shown in Figures 9(a)-9(c). Figure 9(d) plots the 


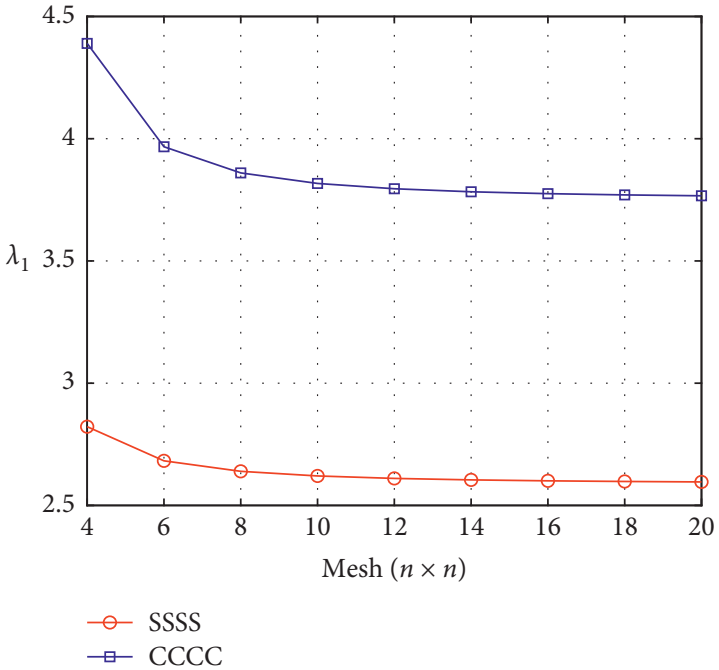

(a)

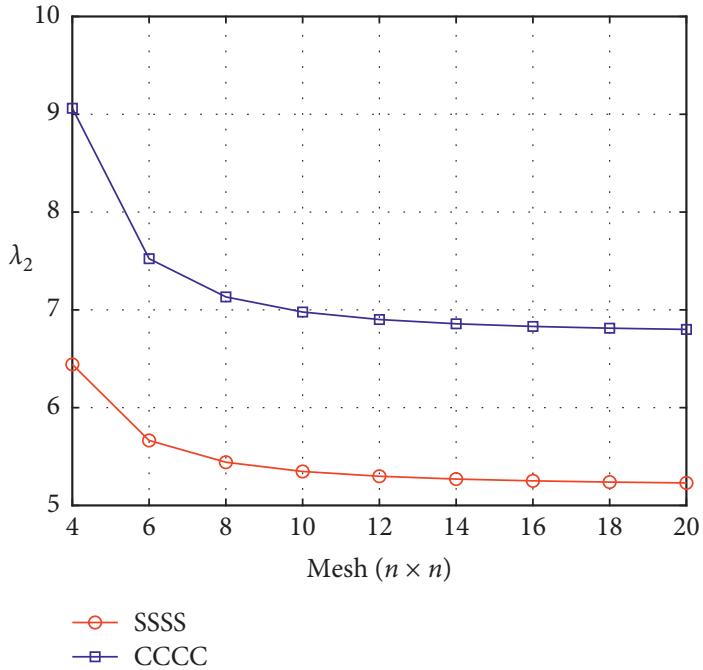

(b)

FIGURE 5: The convergence of the dimensionless frequencies of the plate: (a) dimensionless frequency $\lambda_{1}$; (b) dimensionless frequency $\lambda_{2}$.

TABle 1: Dimensionless frequencies of plates.

\begin{tabular}{|c|c|c|c|c|c|c|c|c|c|}
\hline Plates & $K_{1}$ & $K_{2}$ & Authors & $\lambda_{1}$ & $\Delta(\%)$ & $\lambda_{2}$ & $\Delta(\%)$ & $\lambda_{3}$ & $\Delta(\%)$ \\
\hline \multirow{10}{*}{$\begin{array}{l}\text { SSSS } \\
v=0.3 \\
h / a=0.1\end{array}$} & \multirow{5}{*}{200} & \multirow{5}{*}{10} & Ferreira et al. [6] & 2.7902 & & 5.3452 & & 7.8255 & \\
\hline & & & Zhou et al. [5] & 2.7756 & 0.52 & 5.2954 & 0.93 & 7.7279 & 1.25 \\
\hline & & & Xiang et al. [3] & 2.7842 & 0.22 & 5.3043 & 0.77 & 7.7287 & 1.24 \\
\hline & & & MITC3 & 2.7874 & 0.10 & 5.3258 & 0.36 & 7.7719 & 0.68 \\
\hline & & & ES-MITC3 & 2.7887 & 0.05 & 5.3362 & 0.17 & 7.7971 & 0.36 \\
\hline & \multirow{5}{*}{1000} & \multirow{5}{*}{10} & Ferreira et al. [6] & 3.9844 & & 6.0430 & & 8.3112 & \\
\hline & & & Zhou et al. [5] & 3.9566 & 0.70 & 5.9757 & 1.11 & 8.1954 & 1.39 \\
\hline & & & Xiang et al. [3] & 3.9805 & 0.10 & 6.0078 & 0.58 & 8.2214 & 1.08 \\
\hline & & & MITC3 & 3.9827 & 0.04 & 6.0266 & 0.27 & 8.2619 & 0.59 \\
\hline & & & ES-MITC3 & 3.9836 & 0.02 & 6.0358 & 0.12 & 8.2856 & 0.31 \\
\hline \multirow{5}{*}{$\begin{array}{l}\text { CCCC } \\
v=0.15 \\
h / a=0.015\end{array}$} & \multirow{5}{*}{1390.2} & \multirow{5}{*}{166.83} & Ferreira et al. [6] & 8.1669 & & 12.821 & & 16.842 & \\
\hline & & & Zhou et al. [5] & 8.1675 & 0.01 & 12.823 & 0.02 & 16.833 & 0.05 \\
\hline & & & Omurtag et al. [4] & 8.1375 & 0.36 & 12.898 & 0.60 & 16.932 & 0.53 \\
\hline & & & MITC3 & 8.1842 & 0.21 & 12.909 & 0.69 & 17.010 & 1.00 \\
\hline & & & ES-MITC3 & 8.1729 & 0.07 & 12.872 & 0.40 & 16.939 & 0.58 \\
\hline
\end{tabular}

Note that $\Delta(\%)=100 \times\left(\left|\lambda_{\mathrm{pr}}-\lambda_{\mathrm{re}}\right| /\left|\lambda_{\mathrm{re}}\right|\right)$ with $\lambda_{\mathrm{pr}}$ and $\lambda_{\mathrm{re}}$ which are the dimensionless frequencies of the present method and the dimensionless frequencies in references, respectively.

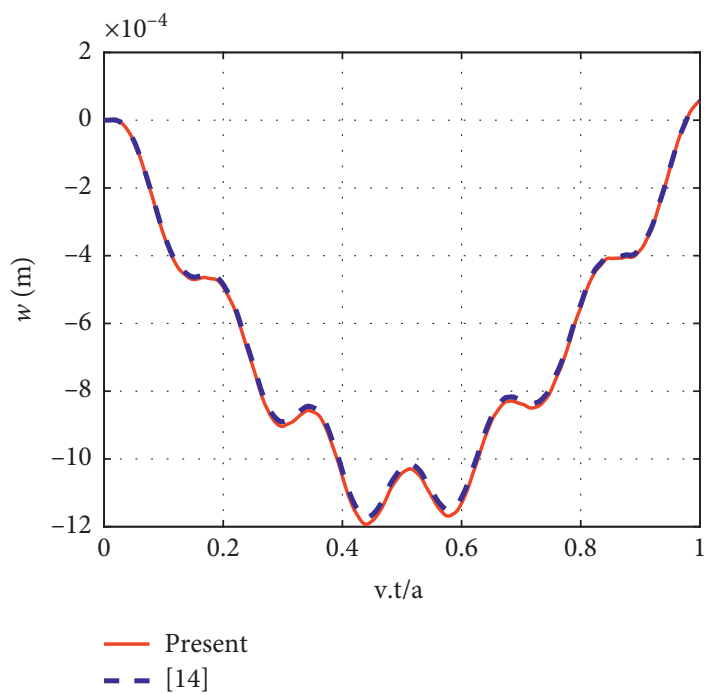

FIGURE 6: Dynamic deflections of the central point of the SSSS rectangular plate versus time. 
TABLE 2: Material properties of the FGP plate.

\begin{tabular}{lccc}
\hline Material properties & Young's moduli & Mass densities & Poisson's ratio \\
\hline Top surface & $E_{t}=14.4 \mathrm{GPa}$ & $\rho_{t}=12200 \mathrm{~kg} / \mathrm{m}^{3}$ & $v=0.38$ \\
Bottom surface & $E_{b}=1.44 \mathrm{GPa}$ & $\rho_{b}=1220 \mathrm{~kg} / \mathrm{m}^{3}$ & $v=0.38$ \\
\hline
\end{tabular}

TABLE 3: First six natural frequencies of the FGP plate on the EFTIM (Hz).

\begin{tabular}{lccccc}
\hline$\lambda_{1}$ & $\lambda_{2}$ & $\lambda_{3}$ & $\lambda_{4}$ & $\lambda_{5}$ & $\lambda_{6}$ \\
\hline 2.5424 & 3.5324 & 5.5324 & 6.8785 & 8.1836 & 8.3744 \\
\hline
\end{tabular}

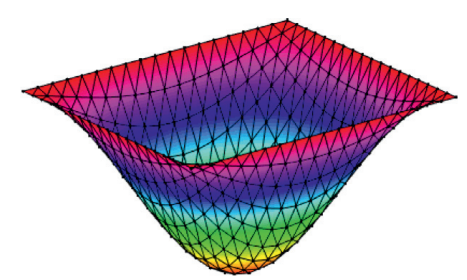

(a)

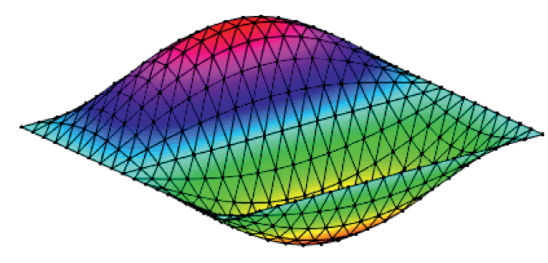

(d)

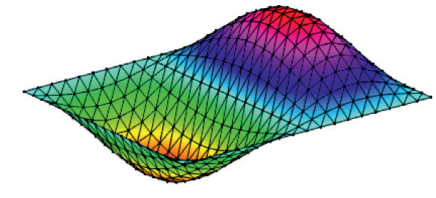

(b)

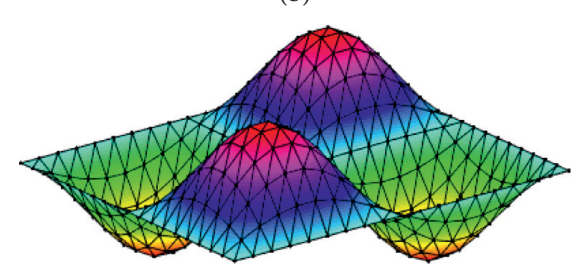

(e)

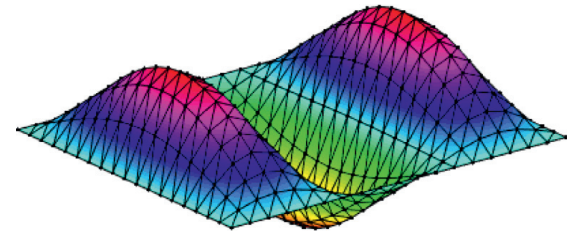

(c)

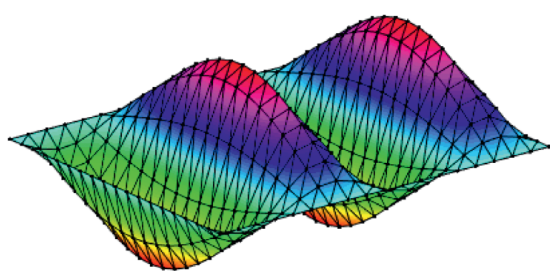

(f)

Figure 7: The first six mode shapes of the FGP plate on EFTIM. (a) Mode 1. (b) Mode 2. (c) Mode 3. (d) Mode 4. (e) Mode 5. (f) Mode 6.

stress at the center of the plate through thickness when the load moves to the midpoint of the plate. The maximum deflections, velocities, and stresses at the central point of the plate are illustrated in Table 5. From Figure 9 and Table 5, it can be seen that the deflection along the $z$-axis of the plate decreases slightly when the velocity of the moving load is less than $10 \mathrm{~m} / \mathrm{s}$ but increases rapidly when the velocity of the moving load varies from 10 to $25 \mathrm{~ms}$. These results demonstrate that the speed of the moving load affects significantly the dynamic response of the FGP plate.

6.3. Influence of the Parameters of EFTIM. In this example, we study the effect of Winkler foundation stiffness $k_{1}$ on the dynamic responses of the FGP plate in case 1 of the porosity distribution. We examine $k_{1}$ varying from 0 to 100 , and the shear layer stiffness of the Pasternak foundation is fixed with $k_{2}=5 \mathrm{kPa} \cdot \mathrm{m}$. The moving load with magnitude $P=5 \mathrm{kN}$ moves along the edge of the plate $y=b / 2$ with velocity $v=$ $5 \mathrm{~m} / \mathrm{s}$. The responses of deflection, velocity, and stress $(z=$ 0 ) at the center of the plate versus time are shown in Figures 10(a)-10(c). Figure 10(d) presents the central stress of the plate through thickness when the load moves to the midpoint of the plate. The maximum deflections, velocities, and stresses at the central point of the plate are illustrated in
Table 6. From these numerical results, it can be seen that the increase of the Winkler foundation stiffness $k_{1}$ leads to the increase of the FGP plate stiffness and hence makes decrease the deflection of the plate.

Next, we consider the effects of shear layer stiffness of Pasternak foundation $k_{2}$ on the dynamic response of the FGP plate in case 1 of the porosity distribution. The moving load with magnitude $P=5 \mathrm{kN}$ moves along the edge of the plate $y=b / 2$ with velocity $v=5 \mathrm{~m} / \mathrm{s}$. The variation of the shear layer stiffness of the Pasternak foundation is given by $k_{2}=0,5,25,50,100 \mathrm{kPa} \cdot \mathrm{m}$, and the Winkler foundation stiffness is fixed at $k_{1}=50 \mathrm{kPa} / \mathrm{m}$. The responses of deflection, velocity, and stress $(z=0)$ at the center of the plate versus time are shown in Figures 11(a)-11(c). Figure 11(d) shows the central stress of the plate through thickness when the load moves to the midpoint of the plate. The maximum deflections, velocities, and stresses at the central point of the plate are illustrated in Table 7. From these numerical results, it can be found that the increase of the foundation stiffness $k_{2}$ leads to the decrease of the deflection of the plate. This implies that the increase of the Winkler foundation stiffness $k_{2}$ leads to the increase of stiffness of FGP plates. However, when the foundation stiffness factor $k_{2}$ is less than 50 , the response of the deflection of the plate can be negligible, and 


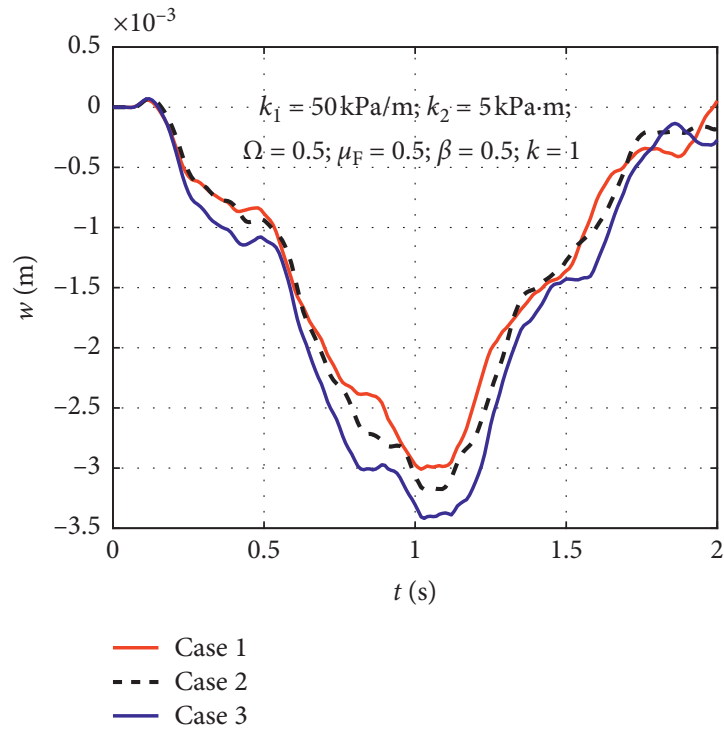

(a)

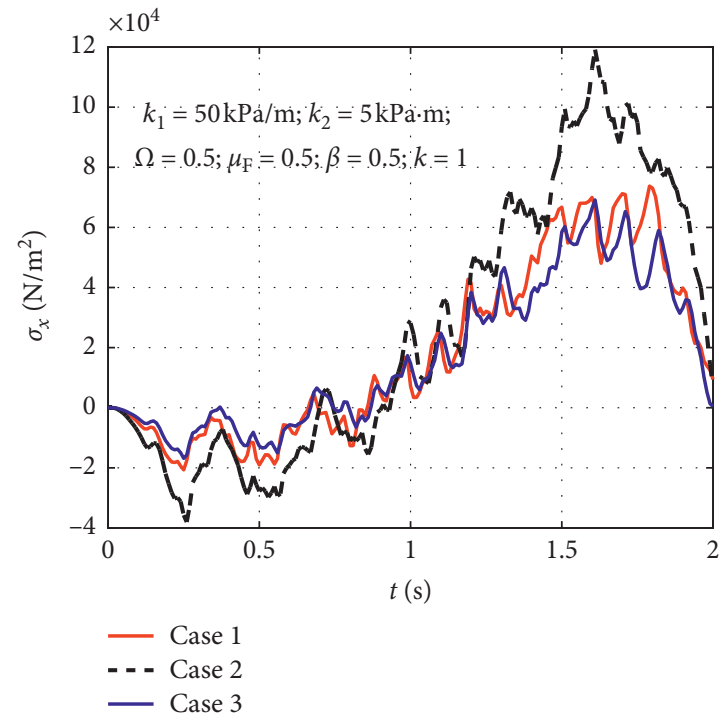

(c)

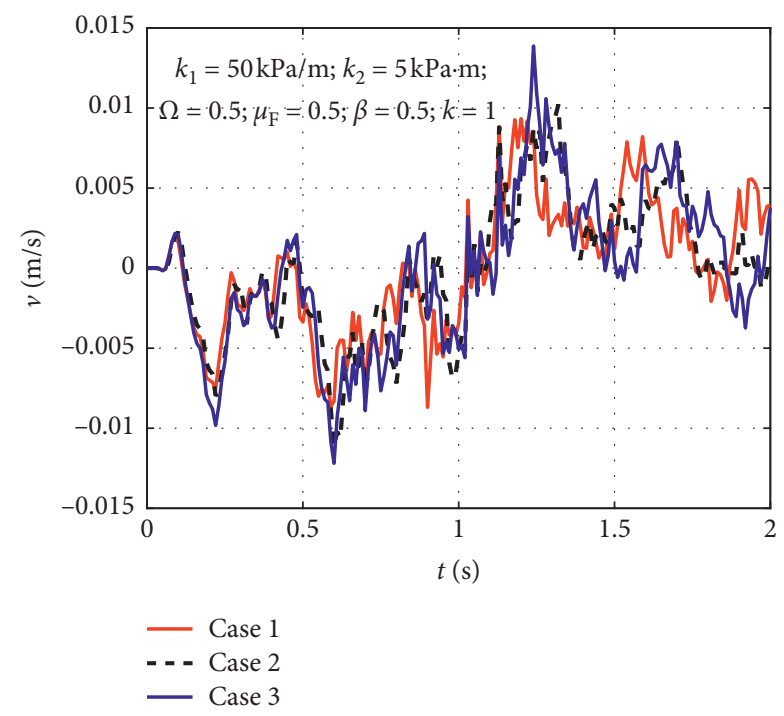

(b)

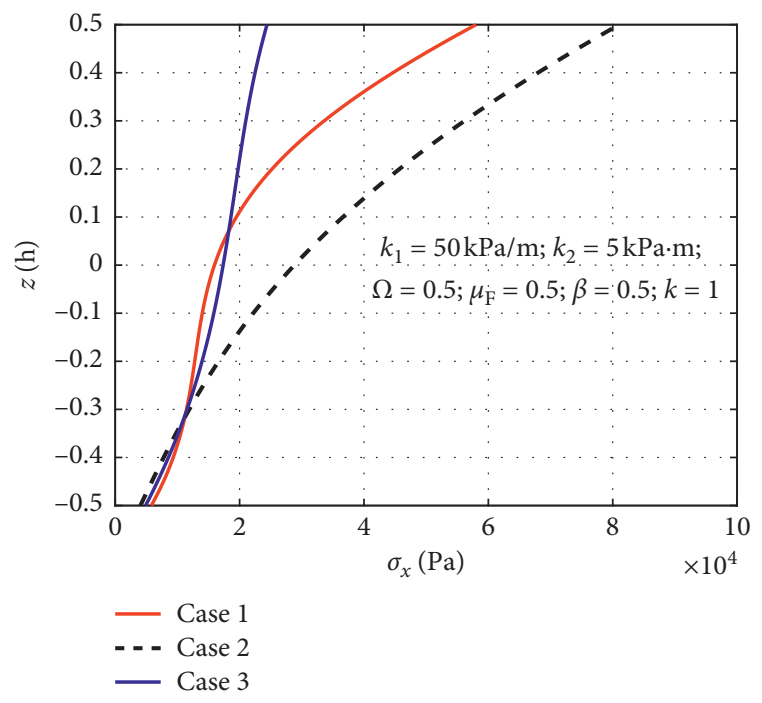

(d)

Figure 8: The responses of deflection, velocity, and stress at the central point of the plate with three different cases of the porosity distribution: (a) deflection versus time; (b) velocity versus time; (c) stress $\sigma_{x}$ versus time; (d) stress $\sigma_{x}$ through thickness.

TABle 4: Maximum deflections, velocities, and stress at the central point of the plate versus time.

\begin{tabular}{llll}
\hline Maximum values & Case 1 & Case 2 & Case 3 \\
\hline$w(\mathrm{~m})$ & 0.0030 & 0.0032 & 0.0034 \\
$v(\mathrm{~m} / \mathrm{s})$ & 0.0087 & 0.0112 & 0.0122 \\
$\sigma_{x}(\mathrm{~Pa}) \times 10^{5}$ & 0.7373 & 1.1914 & 0.6913 \\
\hline
\end{tabular}

the effect of factor $k_{2}$ on the stiffness of the plate is less than the effect of factor $k_{1}$.

To investigate the effects of the featured-index of the mass of the foundation $\beta$ on the dynamic response of the FGP plate in case 1 of the porosity distribution, we consider the plate under the moving load $P=5 \mathrm{kN}$ traveling along the edge of the plate $y=b / 2$ with the velocity $v=5 \mathrm{~m} / \mathrm{s}$ and other parameters given as the Winkler foundation stiffness $k_{1}=50 \mathrm{kPa} / \mathrm{m}$, the shear layer stiffness of Pasternak foundation $k_{2}=5 \mathrm{kPa} \cdot \mathrm{m}$, and the variation of the mass of the foundation $\beta=0,0.25,0.5,0.75$, and 1 . The responses of deflection, 


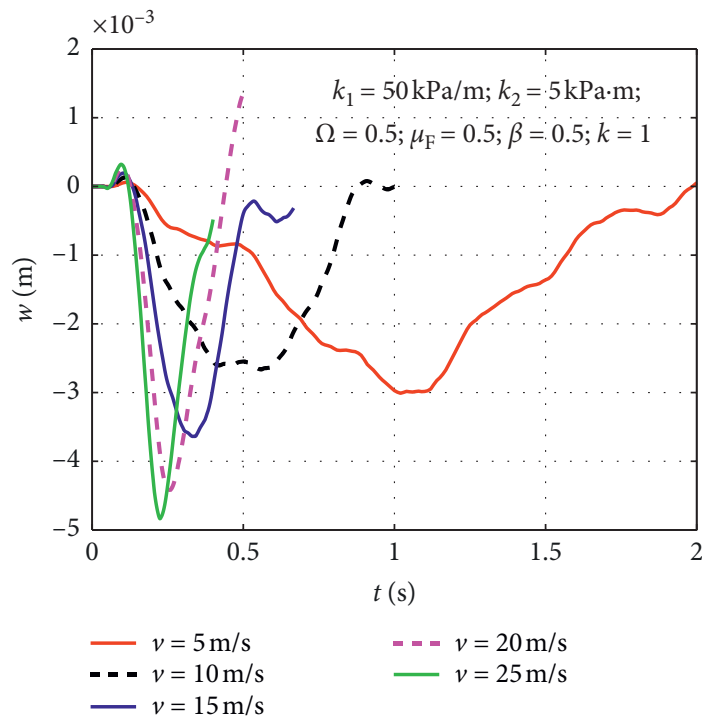

(a)

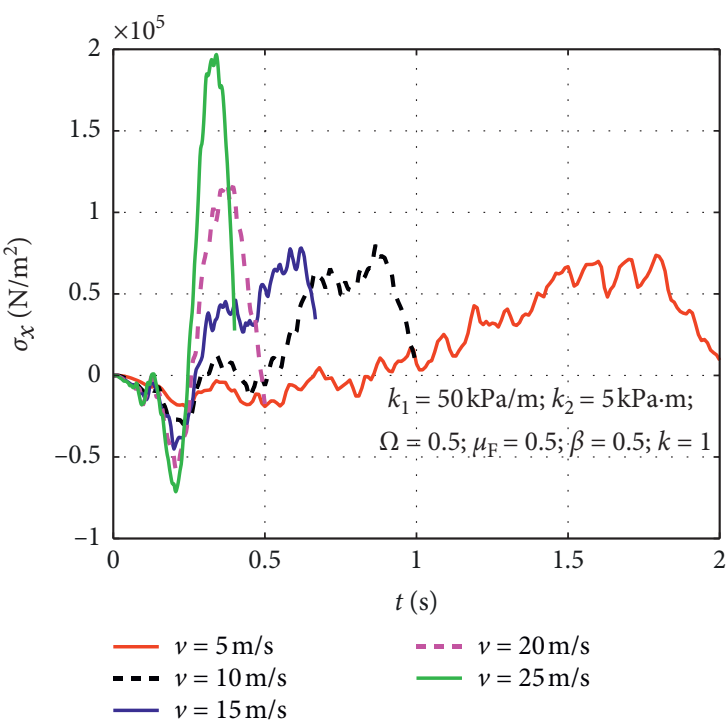

(c)

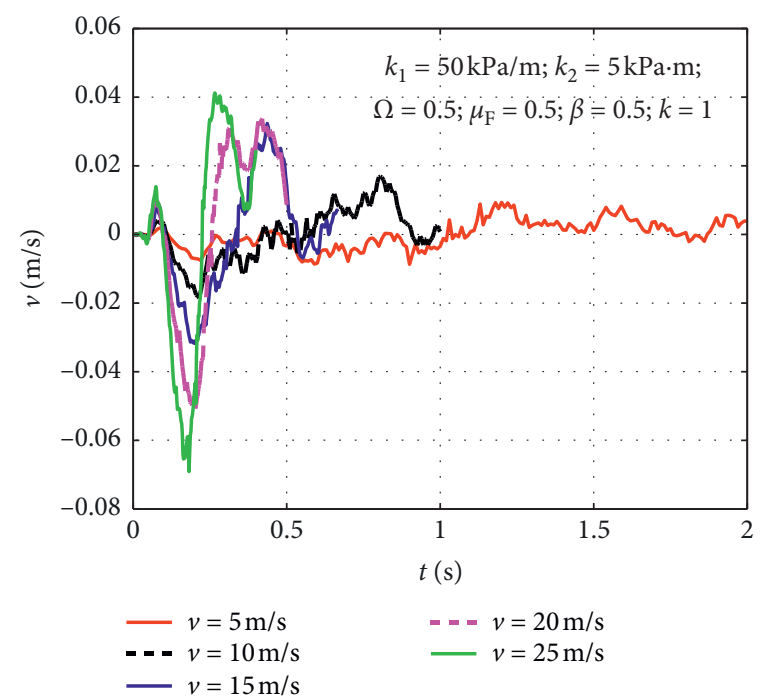

(b)

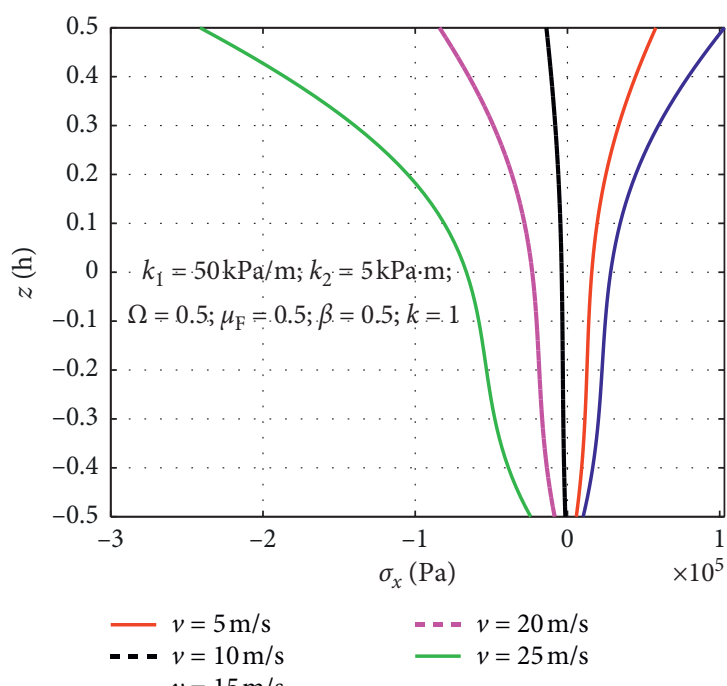

(d)

FIGURE 9: The responses of deflections, velocities, and stresses at the central point of the FGP plate versus time with the variation of the moving load velocity $v$ : (a) deflection $w$ versus time; (b) velocity $v$ versus time; (c) stress $\sigma_{x}$ versus time; (d) stress $\sigma_{x}$ through thickness.

TABLE 5: Maximum deflections, velocities, and stresses at the central point of the FGP plate versus time.

\begin{tabular}{|c|c|c|c|c|c|}
\hline Maximum values & $v=5 \mathrm{~m} / \mathrm{s}$ & $v=10 \mathrm{~m} / \mathrm{s}$ & $v=15 \mathrm{~m} / \mathrm{s}$ & $v=20 \mathrm{~m} / \mathrm{s}$ & $v=25 \mathrm{~m} / \mathrm{s}$ \\
\hline$w(\mathrm{~m})$ & 0.0030 & 0.0027 & 0.0036 & 0.0030 & 0.0048 \\
\hline$v(\mathrm{~m} / \mathrm{s})$ & 0.0087 & 0.0184 & 0.0318 & 0.0508 & 0.0691 \\
\hline$\sigma_{x}(\mathrm{~Pa}) \times 10^{5}$ & 0.7373 & 0.8007 & 1.0311 & 1.1827 & 1.9683 \\
\hline
\end{tabular}

velocity, and stress $(z=0)$ at the center of the plate versus time are shown in Figures 12(a)-12(c). Figure 12(d) plots the central stress of the plate through thickness when the load moves to the midpoint of the plate. The maximum deflections, velocities, and stresses at the central point of the plate are illustrated in Table 8 . From these numerical results, it can be seen that the increase of the mass of the foundation $\beta$ varying from 0 to 1 leads to the increase of the deflection of the plate, but this change is not much. This demonstrates that the mass of the EF involved in the plate's vibration makes decrease the stiffness of FGP plates. 


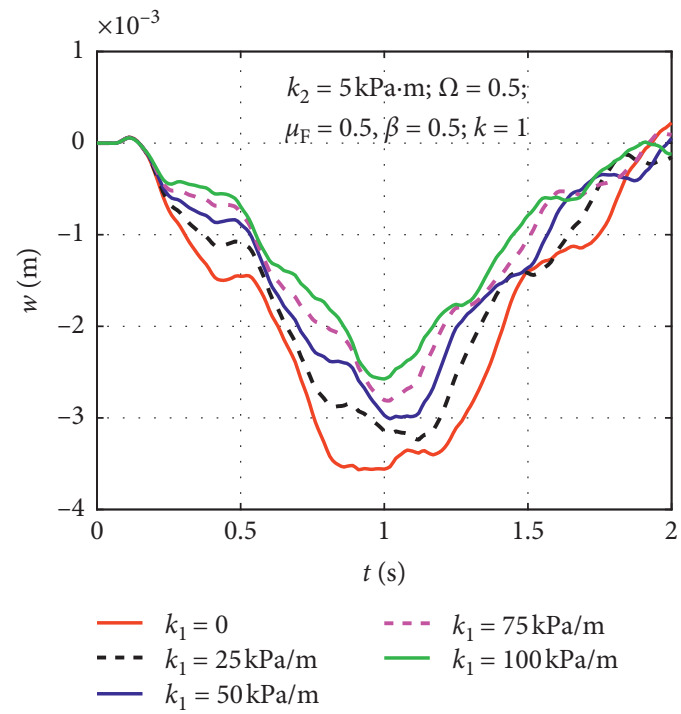

(a)

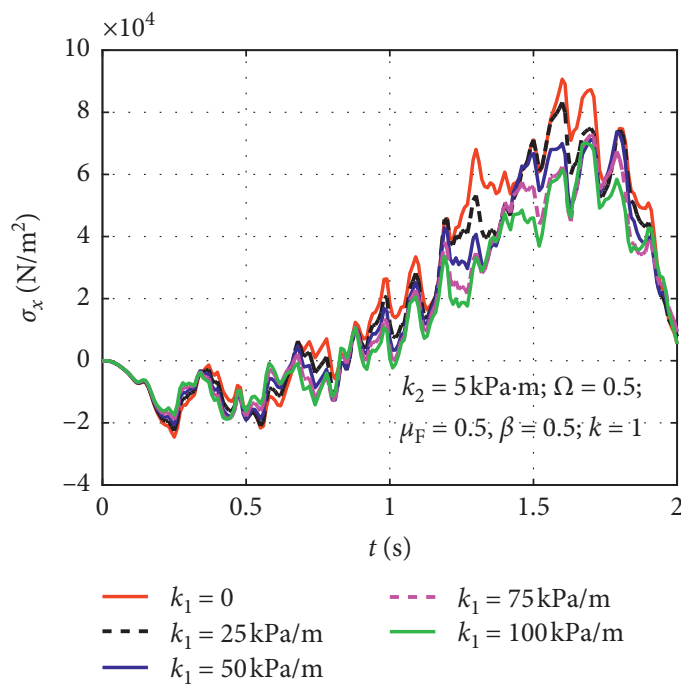

(c)

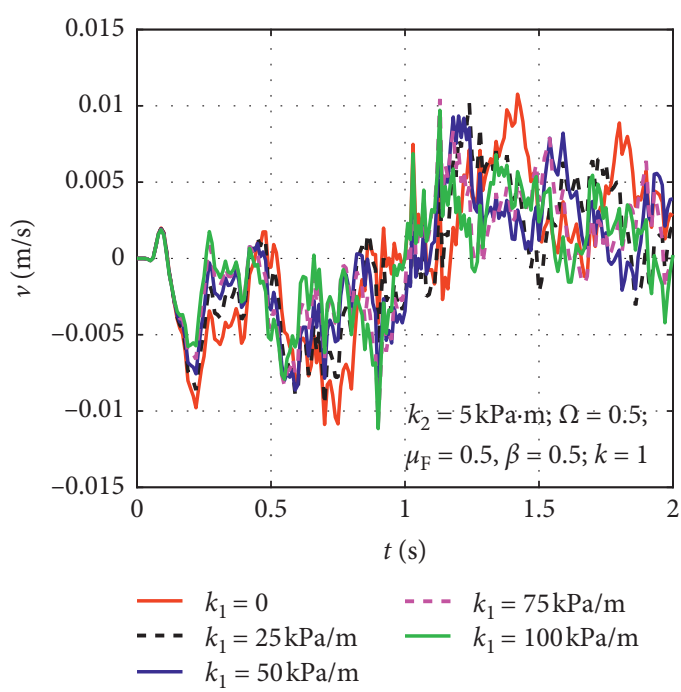

(b)

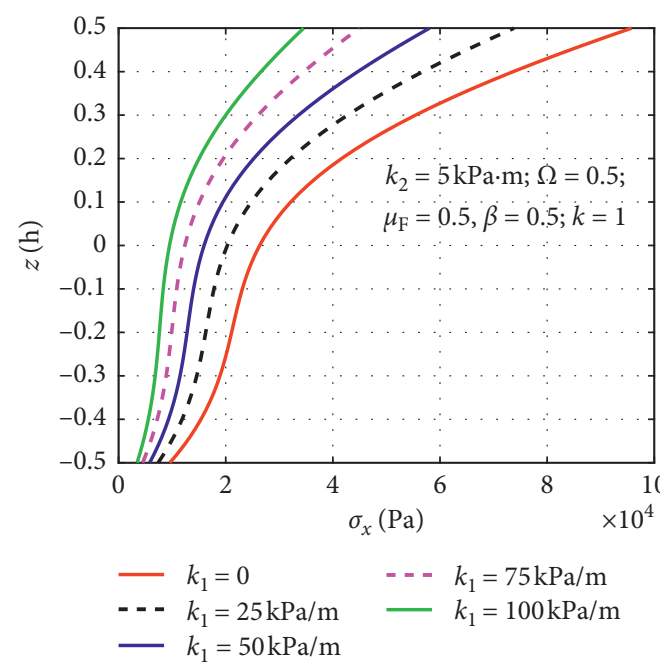

(d)

Figure 10: The responses of deflections, velocities, and stresses at the central point of the FGP plate versus time with the variation of the foundation stiffness $k_{1}$ : (a) deflection $w$ versus time; (b) velocity $v$ versus time; (c) stress $\sigma_{x}$ versus time; (d) stress $\sigma_{x}$ through thickness.

TABle 6: Maximum deflections, velocities, and stresses at the central point of the FGP plate versus time.

\begin{tabular}{lccccc}
\hline Maximum values & $k_{1}=0 \mathrm{kPa} / \mathrm{m}$ & $k_{1}=25 \mathrm{kPa} / \mathrm{m}$ & $k_{1}=50 \mathrm{kPa} / \mathrm{m}$ & $k_{1}=75 \mathrm{kPa} / \mathrm{m}$ & $k_{1}=100 \mathrm{kPa} / \mathrm{m}$ \\
\hline$w(\mathrm{~m})$ & 0.0036 & 0.0032 & 0.0030 & 0.0028 & 0.0026 \\
$v(\mathrm{~m} / \mathrm{s})$ & 0.0109 & 0.0096 & 0.0087 & 0.0108 & 0.0112 \\
$\sigma_{x}(\mathrm{~Pa}) \times 10^{5}$ & 0.9066 & 0.8318 & 0.5802 & 0.7279 & 0.7015 \\
\hline
\end{tabular}

6.4. Influences of the Parameters-FGP to the Dynamic Response of the FGP Plate on the EFTIM. In this example, we study the effects of the material properties on the dynamic response of the FGP plate in case 1 of the porosity distribution. The power-law index is chosen as $k=0,5,10,20,50$, and the porosity distribution $\Omega$ varies from 0 to 1 . The SSSS rectangular FGP plate rests on the EFTIM with parameter $\beta=0.5, \mu_{\mathrm{F}}=0.5, k_{1}=50 \mathrm{kPa} / \mathrm{m}$, and $k_{2}=5 \mathrm{kPa} \cdot \mathrm{m}$. The responses of deflections, velocities, and stresses at the central point of the FGP plate are shown in Figures 13 and 14, and these maximum values are presented in Tables 9 and 10 . From Figure 13 and Table 9, it can be seen that the increase 


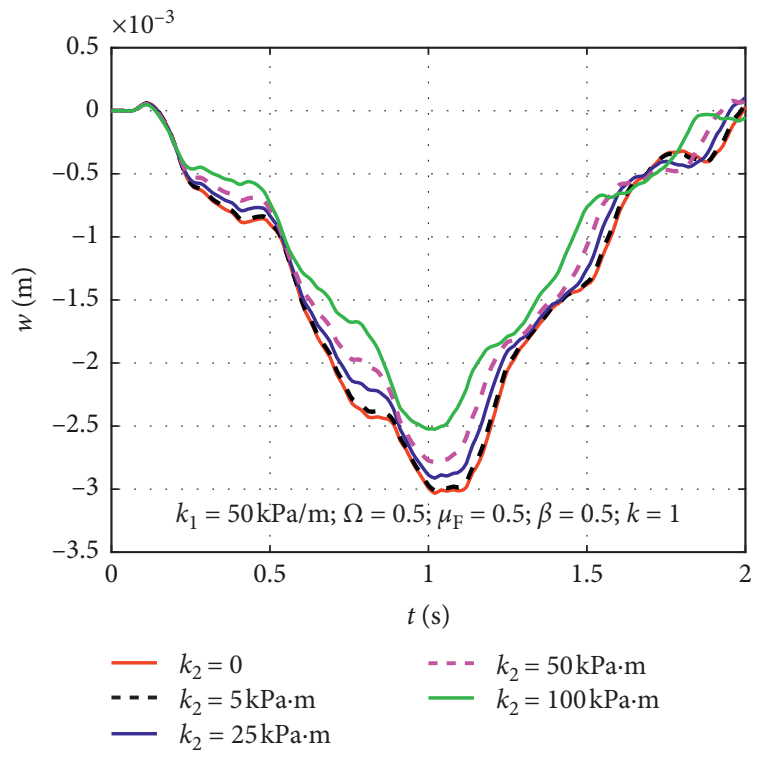

(a)

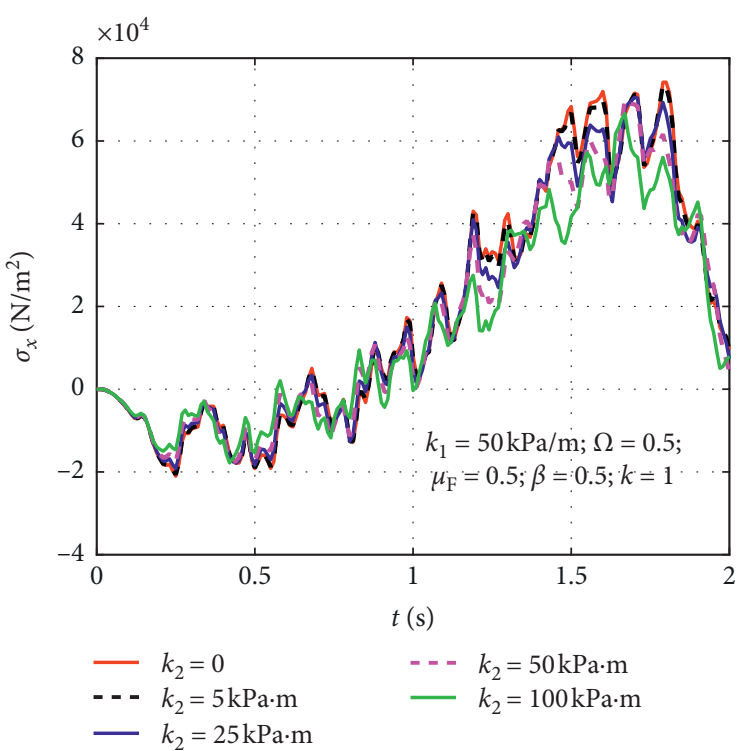

(c)

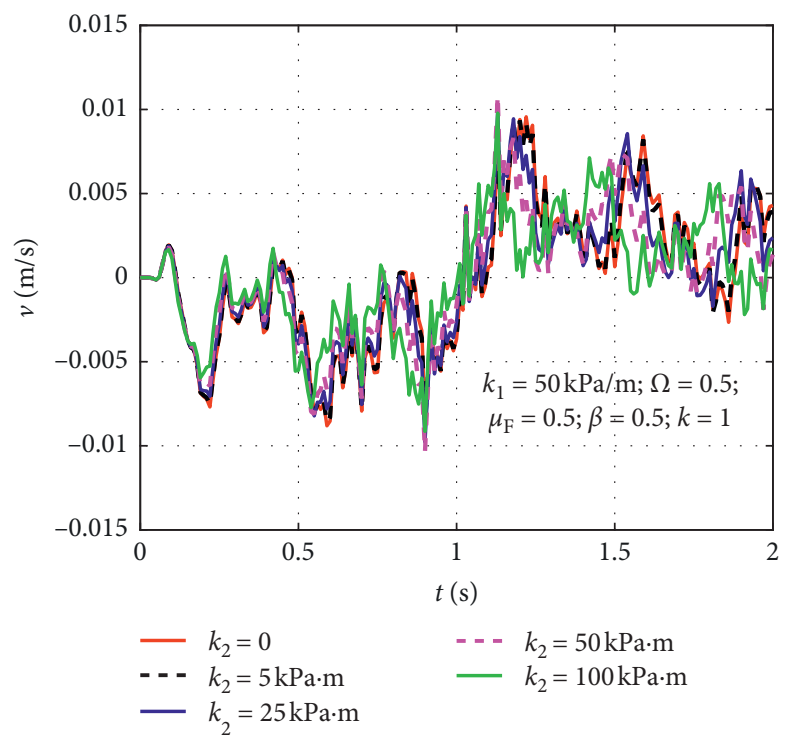

(b)

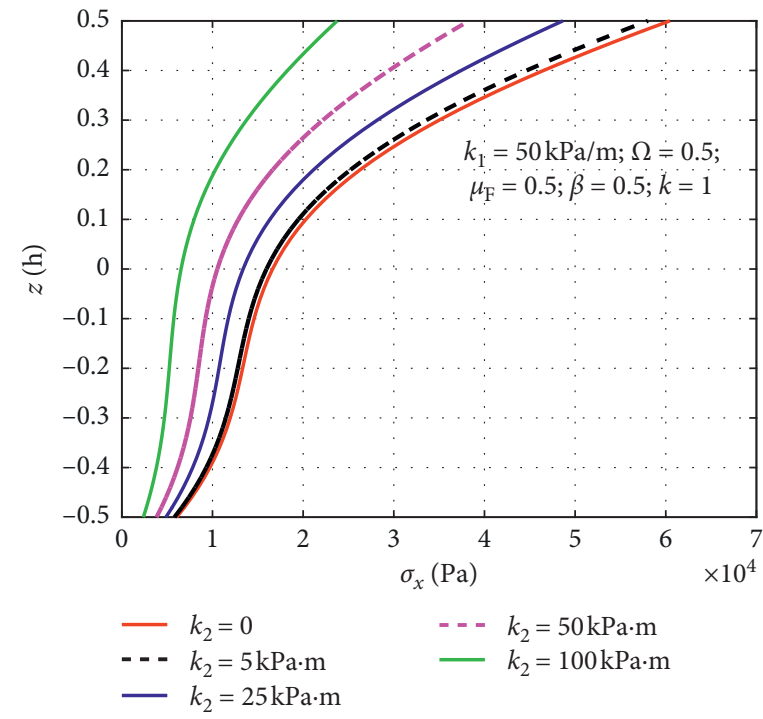

(d)

Figure 11: The responses of deflections, velocities, and stresses at the central point of the plate versus time with the variation of the foundation stiffness $k_{2}$ : (a) deflection $w$ versus time; (b) velocity $v$ versus time; (c) stress $\sigma_{x}$ versus time; (d) stress $\sigma_{x}$ through thickness.

TABle 7: Maximum deflections, velocities, and stresses at the central point of the FGP plate versus time.

\begin{tabular}{lccccc}
\hline Maximum values & $k_{2}=0 \mathrm{kPa} \cdot \mathrm{m}$ & $k_{2}=5 \mathrm{kPa} \cdot \mathrm{m}$ & $k_{3}=25 \mathrm{kPa} \cdot \mathrm{m}$ & $k_{4}=50 \mathrm{kPa} \cdot \mathrm{m}$ & 0.0028 \\
\hline$w(\mathrm{~m})$ & 0.0030 & 0.0030 & 0.0029 & $k_{5}=100 \mathrm{kPa} \cdot \mathrm{m}$ \\
$v(\mathrm{~m} / \mathrm{s})$ & 0.0088 & 0.0087 & 0.0098 & 0.0104 & 0.0025 \\
$\sigma_{x}(\mathrm{~Pa}) \times 10^{5}$ & 0.7421 & 0.7372 & 0.4865 & 0.70274 & 0.0091 \\
\hline
\end{tabular}

of the power-law index $k$ leads to the increase of the response of the deflections and velocities of the plate because the increase of the power-law index $k$ makes the plate become metal-rich and hence makes decrease the hardness of the plate. However, it is noted that when the porosity distribution $\Omega$ increases, the response of deflections, velocities, and stresses of the plate also increases. This is because the increase of the distribution of porosity makes decrease the stiffness of FGP plates. These results are illustrated in Figure 14 and Table 10. 


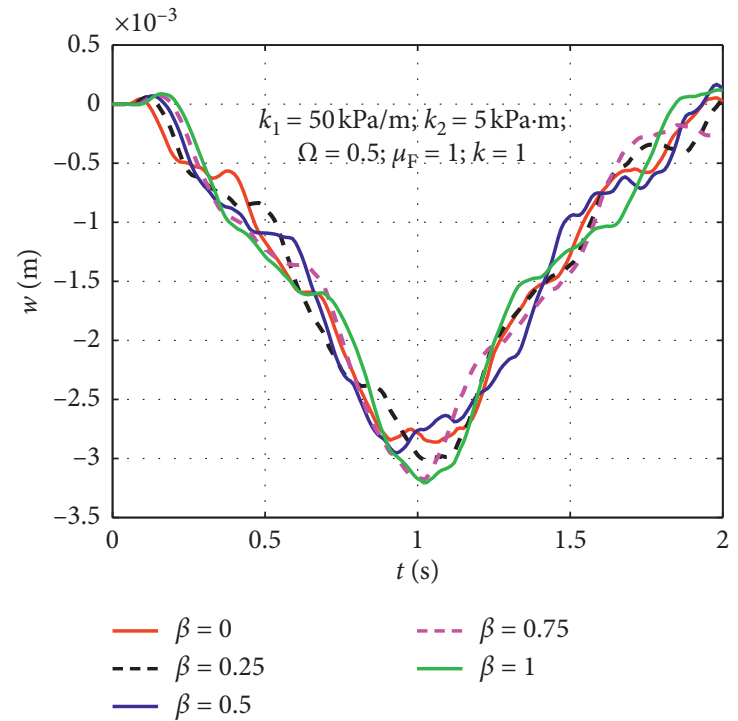

(a)

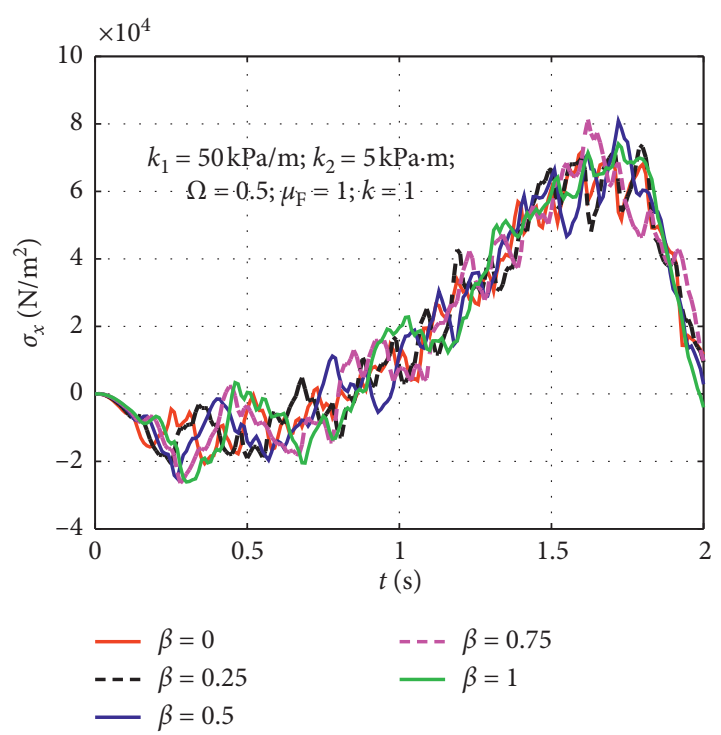

(c)

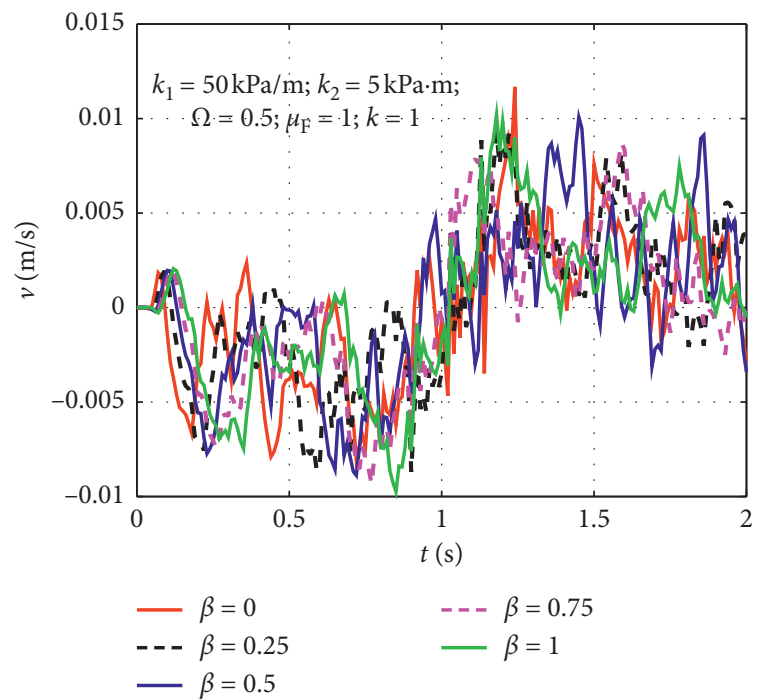

(b)

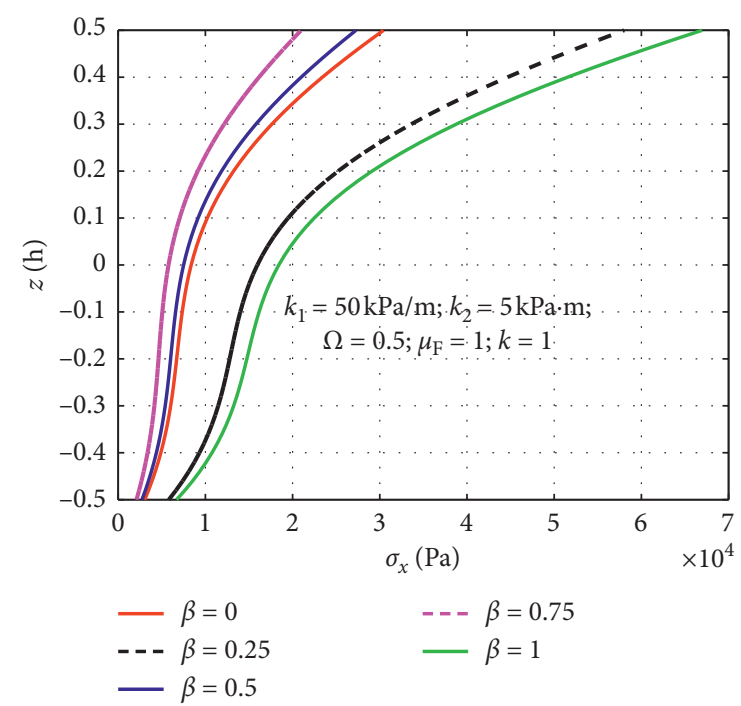

(d)

FIGURE 12: The responses of deflections, velocities, and stresses at the central point of the FGP plate versus time with the variation of mass of the foundation $\beta$; (a) deflection $w$ versus time; (b) velocity $v$ versus time; (c) stress $\sigma_{x}$ versus time; (d) stress $\sigma_{x}$ through thickness.

TABle 8: Maximum deflections, velocities, and stresses at the central point of the FGP plate versus time.

\begin{tabular}{lccccc}
\hline Maximum values & $\beta=0$ & $\beta=2.5$ & $\beta=5$ & $\beta=0.75$ & $\beta=1$ \\
\hline$w(\mathrm{~m})$ & 0.0029 & 0.0030 & 0.0030 & 0.0032 & 0.0093 \\
$v(\mathrm{~m} / \mathrm{s})$ & 0.008 & 0.0087 & 0.0089 & 0.0097 \\
$\sigma_{x}(\mathrm{~Pa}) \times 10^{5}$ & 0.7180 & 0.7372 & 0.2727 & 0.8129 & 0.7406 \\
\hline
\end{tabular}

\section{Conclusions}

This work presents an extension of ES-MITC3 using threenode triangular elements for dynamic analysis of the functionally graded porous (FGP) plates subjected to moving loads resting on the elastic foundation taking into mass (EFTIM). The obtained numerical results of the proposed approach in different contexts are compared with other available solutions in the literature. The effect of the geometrical parameters and material properties on the dynamic response of the FGP plate resting on the EFTIM is also examined in detail. From the present formulation and the numerical results, we can withdraw some following points: 


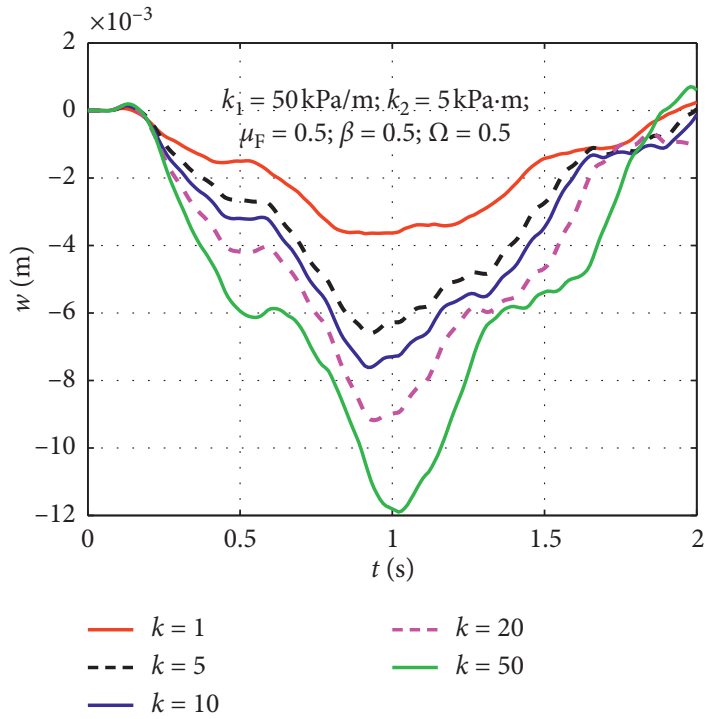

(a)

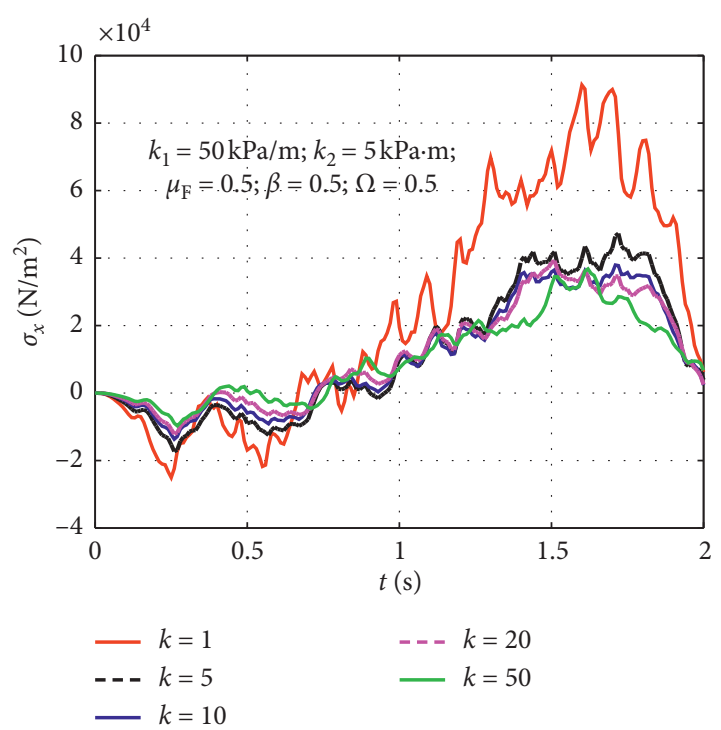

(c)

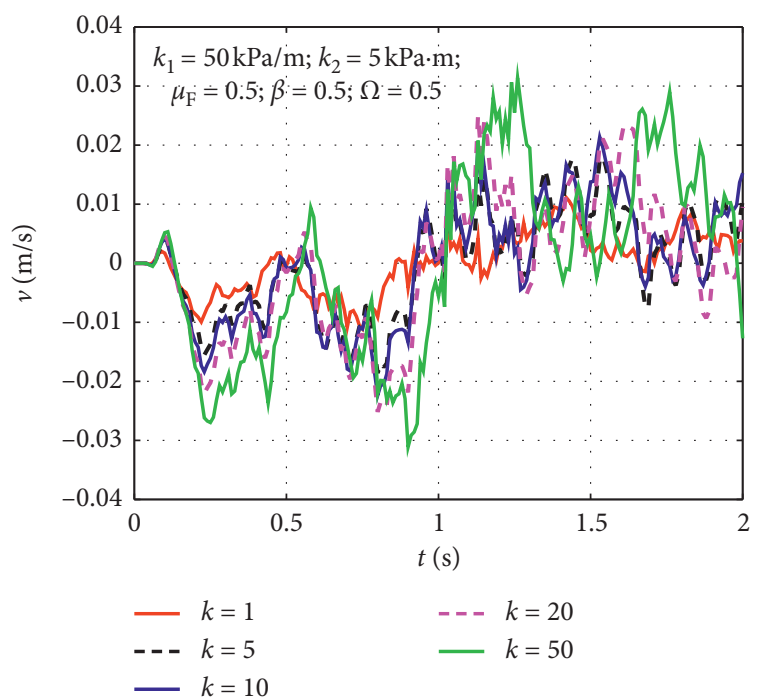

(b)

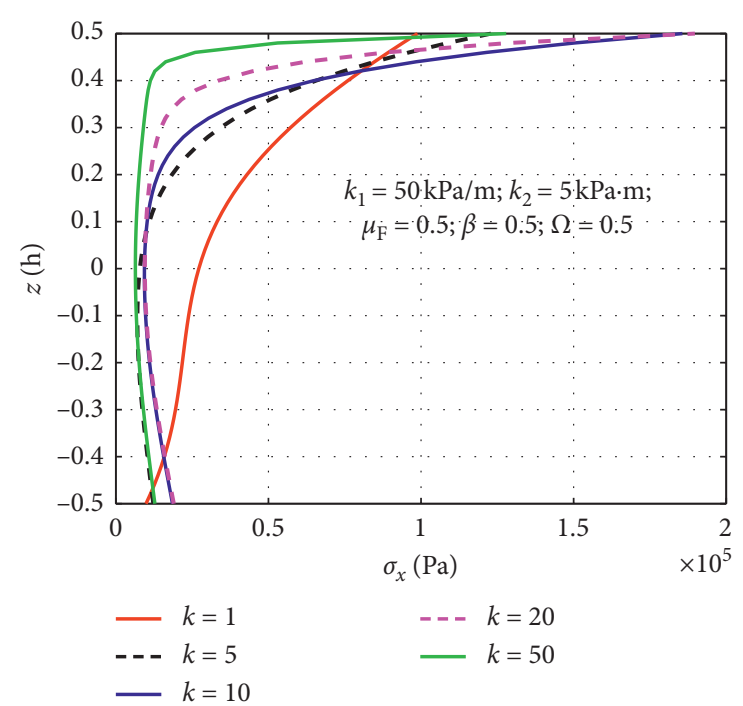

(d)

FIGURE 13: The responses of deflections, velocities, and stresses at the central point of the FGP plate versus time with the variation of the foundation stiffness $k$ : (a) deflection $w$ versus time; (b) velocity $v$ versus time; (c) stress $\sigma_{x}$ versus time; (d) stress $\sigma_{x}$ through thickness.

(i) The numerical results by the ES-MITC3 element agree excellently with those of some other compared elements and have better accuracy than that of the original MITC3 element

(ii) The EFTIM model can be used to accurately describe the EF model

(iii) The increase in foundation parameters $k_{1}$ and $k_{2}$ of the EF leads to the increase in the stiffness of the FGP plates (iv) The increase in the mass of the EF leads to decrease in the stiffness of the FGP plates

(v) The material parameters $k$ and $\Omega$ and the porosity distribution of the FGP plates significantly affect the dynamic response of the FGP plates

(vi) The increase in the velocity of the moving load leads to the increase in the vibration of the FGP plates

It is noted that, besides the advantages of using the firstorder shear deformation theory (FSDT) regarding the 


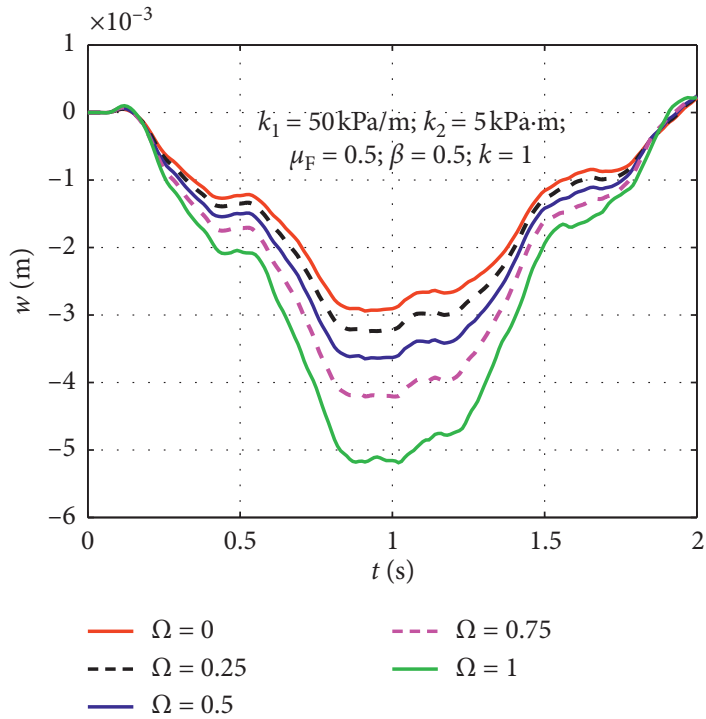

(a)

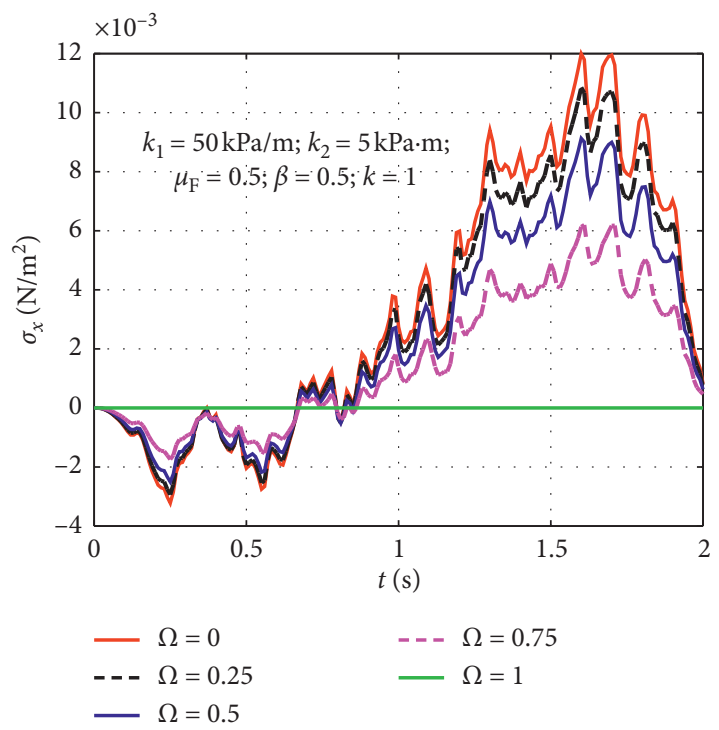

(c)

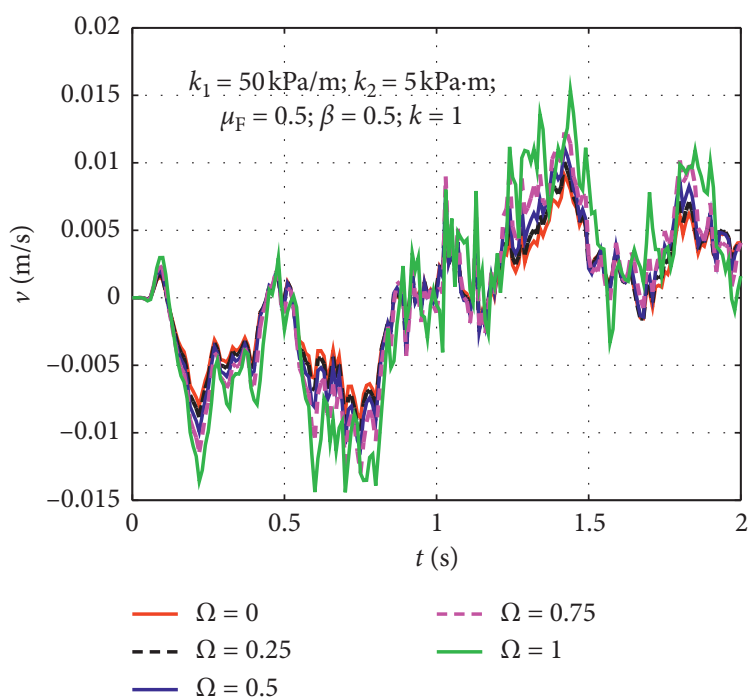

(b)

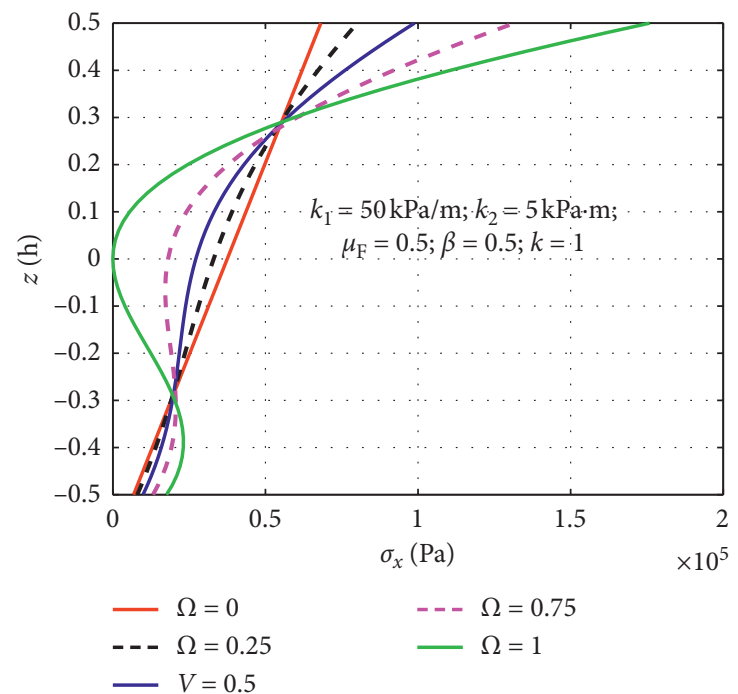

(d)

FIgURE 14: The responses of deflections, velocities, and stresses at the central point of the FGP plate versus time with the variation of the porosity distribution $\Omega$ : (a) deflection $w$ versus time; (b) velocity $v$ versus time; (c) stress $\sigma_{x}$ versus time; (d) stress $\sigma_{x}$ through thickness.

Table 9: Maximum deflections, velocities, and stresses at the central point of the FGP plate versus time $(\Omega=0.5)$.

\begin{tabular}{lcccrr}
\hline Maximum values & $k=1$ & $k=5$ & $k=10$ & $k=20$ & $k=50$ \\
\hline$w(\mathrm{~m})$ & 0.0036 & 0.0066 & 0.0076 & 0.0092 & 0.0119 \\
$v(\mathrm{~m} / \mathrm{s})$ & 0.0111 & 0.0186 & 0.0224 & 0.0311 \\
$\sigma_{x}(\mathrm{~Pa}) \times 10^{5}$ & 0.9129 & 0.4729 & 1.8563 & 0.3923 & 0.3679 \\
\hline
\end{tabular}

Table 10: Maximum deflections, velocities, and stresses at the central point of the FGP plate versus time $(k=1)$.

\begin{tabular}{|c|c|c|c|c|c|}
\hline Maximum values & $\Omega=0$ & $\Omega=0.25$ & $\Omega=0.5$ & $\Omega=0.75$ & $\Omega=1$ \\
\hline$w(\mathrm{~m})$ & 0.0029 & 0.0032 & 0.0036 & 0.0042 & 0.0052 \\
\hline$v(\mathrm{~m} / \mathrm{s})$ & 0.0029 & 0.0032 & 0.0036 & 0.0042 & 0.0052 \\
\hline$\sigma_{x}(\mathrm{~Pa}) \times 10^{5}$ & 1.1995 & 1.0858 & 0.9884 & 0.6197 & 0 \\
\hline
\end{tabular}


simplicity in formulations and computational efficiency, the proposed method also has a limit regarding using the FSDT to approximate displacement fields of the FGP plates. This limit somehow leads to the limited accuracy and hence should be a topic for improvement in upcoming studies.

\section{Data Availability}

The data used to support the findings of this study are included within the article.

\section{Conflicts of Interest}

The authors declare that they have no conflicts of interest.

\section{Acknowledgments}

This research was funded by the Vietnam National Foundation for Science and Technology Development (NAFOSTED) under Grant no. 107.02-2019.330.

\section{References}

[1] E. Winkler, Die Lehre von der Elasticitaet und Festigkeit, Dominicus, Prague, Czech Republic, 1867.

[2] P. L. Pasternak, On a New Method of Analysis of an Elastic Foundation by Means of Two Foundation Constants, Gosudarstvennoe Izdatelstvo Literaturi po Stroitelstvu i Arkhitekture, 1954, pp. 1-56, Gosudarstvennoe Izdatelstvo Literaturi po Stroitelstvu i Arkhitekture, Moscow, Russia, in Russian.

[3] Y. Xiang, C. M. Wang, and S. Kitipornchai, "Exact vibration solution for initially stressed mindlin plates on Pasternak foundations," International Journal of Mechanical Sciences, vol. 36, no. 4, pp. 311-316, 1994.

[4] M. H. Omurtag, A. Özütok, A. Y. Aköz, and Y. Özçelikörs, "Free vibration analysis of Kirchhoff plates resting on elastic foundation by mixed finite element formulation based on gâteaux differential," International Journal for Numerical Methods in Engineering, vol. 40, no. 2, pp. 295-317, 1997.

[5] D. Zhou, Y. K. Cheung, S. H. Lo, and F. T. K. Au, "Threedimensional vibration analysis of rectangular thick plates on pasternak foundation," International Journal for Numerical Methods in Engineering, vol. 59, no. 10, pp. 1313-1334, 2004.

[6] A. J. M. Ferreira, C. M. C. Roque, A. M. A. Neves, R. M. N. Jorge, and C. M. M. Soares, "Analysis of plates on Pasternak foundations by radial basis functions," Computational Mechanics, vol. 46, no. 6, pp. 791-803, 2010.

[7] N. D. Duc, D. H. Bich, and P. H. Cong, "Nonlinear thermal dynamic response of shear deformable FGM plates on elastic foundations," Journal of Thermal Stresses, vol. 39, no. 3, pp. 278-297, 2016.

[8] A. Mahmoudi, S. Benyoucef, A. Tounsi, A. Benachour, E. A. Adda Bedia, and S. Mahmoud, "A refined quasi-3D shear deformation theory for thermo-mechanical behavior of functionally graded sandwich plates on elastic foundations," Journal of Sandwich Structures \& Materials, vol. 21, no. 6, pp. 1906-1929, 2019.

[9] T. T. Tran, Q. H. Pham, and T. Nguyen-Thoi, "An edge-based smoothed finite element for free vibration analysis of functionally graded porous (FGP) plates on elastic foundation taking into mass (EFTIM)," Mathematical Problems in Engineering, vol. 2020, Article ID 8278743, 17 pages, 2020.
[10] J.-S. Wu, M.-L. Lee, and T.-S. Lai, "The dynamic analysis of a flat plate under a moving load by the finite element method," International Journal for Numerical Methods in Engineering, vol. 24, no. 4, pp. 743-762, 1987.

[11] L. Frýba, Vibration of Solids and Structures under Moving Loads, vol. 1, Springer Science \& Business Media, Berlin, Germany, 2013.

[12] M. R. Taheri and E. C. Ting, "Dynamic response of plate to moving loads: structural impedance method," Computers \& Structures, vol. 33, no. 6, pp. 1379-1393, 1989.

[13] N. N. Hoang, Y. N. Tan, V. T. Ke et al., “A finite element model for dynamic analysis of triple-layer composite plates with layers connected by shear connectors subjected to moving load," Materials, vol. 12, no. 4, pp. 598-617, 2019.

[14] Q. Song, J. Shi, Z. Liu, and Y. Wan, "Dynamic analysis of rectangular thin plates of arbitrary boundary conditions under moving loads," International Journal of Mechanical Sciences, vol. 117, pp. 16-29, 2016.

[15] M. Zaman, M. C. Taheri, and A. Alvappillai, "Dynamic response of a thick plate on viscoelastic foundation to moving loads," International Journal for Numerical and Analytical Methods in Geomechanics, vol. 15, no. 2, pp. 627-647, 1991.

[16] S.-M. Kim and J. M. Roesset, "Moving loads on a plate on elastic foundation," Journal of Engineering Mechanics, vol. 124, no. 9, pp. 1010-1017, 1998.

[17] M.-H. Huang and D. P. Thambiratnam, "Analysis of plate resting on elastic supports and elastic foundation by finite strip method," Computers \& Structures, vol. 79, no. 29-30, pp. 2547-2557, 2001.

[18] M.-H. Huang and D. P. Thambiratnam, "Dynamic response of plates on elastic foundation to moving loads," Journal of Engineering Mechanics, vol. 128, no. 9, pp. 1016-1022, 2002.

[19] K. Seong-Min and B. F. McCullough, "Dynamic response of plate on viscous Winkler foundation to moving loads of varying amplitude," Engineering Structures, vol. 25, pp. 1179-1188, 2003.

[20] T. T. Tran, Q. H. Pham, and T. Nguyen-Thoi, "Dynamic analysis of sandwich auxetic honeycomb plates subjected to moving oscillator load on elastic foundation," Advances in Materials Science and Engineering, vol. 2020, Article ID 6309130, 16 pages, 2020.

[21] J. Kim, K. K. Żur, and J. N. Reddy, "Bending, free vibration, and buckling of modified couples stress-based functionally graded porous micro-plates," Composite Structures, vol. 209, pp. 879-888, 2019.

[22] S. Coskun, J. Kim, and H. Toutanji, "Bending, free vibration, and buckling analysis of functionally graded porous microplates using a general third-order plate theory," Journal of Composites Science, vol. 3, no. 1, p. 15, 2019.

[23] A. S. Rezaei and A. R. Saidi, "Application of carrera unified formulation to study the effect of porosity on natural frequencies of thick porous-cellular plates," Composites Part B: Engineering, vol. 91, pp. 361-370, 2016.

[24] A. S. Rezaei and A. R. Saidi, "Exact solution for free vibration of thick rectangular plates made of porous materials," Composite Structures, vol. 134, pp. 1051-1060, 2016.

[25] J. Zhao, F. Xie, A. Wang, C. Shuai, J. Tang, and Q. Wang, “A unified solution for the vibration analysis of functionally graded porous (FGP) shallow shells with general boundary conditions," Composites Part B: Engineering, vol. 156, pp. 406-424, 2018.

[26] J. Zhao, F. Xie, A. Wang, C. Shuai, J. Tang, and Q. Wang, "Vibration behavior of the functionally graded porous (FGP) doubly-curved panels and shells of revolution by using a 
semi-analytical method," Composites Part B: Engineering, vol. 157, pp. 219-238, 2019.

[27] Q. Li, D. Wu, X. Chen, L. Liu, Y. Yu, and W. Gao, "Nonlinear vibration and dynamic buckling analyses of sandwich functionally graded porous plate with graphene platelet reinforcement resting on Winkler-Pasternak elastic foundation," International Journal of Mechanical Sciences, vol. 148, pp. 596-610, 2018.

[28] S. Sahmani, M. M. Aghdam, and T. Rabczuk, "Nonlocal strain gradient plate model for nonlinear large-amplitude vibrations of functionally graded porous micro/nano-plates reinforced with GPLs," Composite Structures, vol. 198, pp. 51-62, 2018.

[29] D. Wu, A. Liu, Y. Huang, Y. Huang, Y. Pi, and W. Gao, "Dynamic analysis of functionally graded porous structures through finite element analysis," Engineering Structures, vol. 165, pp. 287-301, 2018.

[30] M. R. Barati and A. M. Zenkour, "Analysis of postbuckling of graded porous GPL-reinforced beams with geometrical imperfection," Mechanics of Advanced Materials and Structures, vol. 26, no. 6, pp. 503-511, 2019.

[31] M. R. Barati and A. M. Zenkour, "Electro-thermoelastic vibration of plates made of porous functionally graded piezoelectric materials under various boundary conditions," Journal of Vibration and Control, vol. 24, no. 10, pp. 19101926, 2018.

[32] A. A. Daikh and A. M. Zenkour, "Free vibration and buckling of porous power-law and sigmoid functionally graded sandwich plates using a simple higher-order shear deformation theory," Materials Research Express, vol. 6, no. 11, Article ID 115707, 2019.

[33] M. Sobhy and A. M. Zenkour, "Porosity and inhomogeneity effects on the buckling and vibration of double-FGM nanoplates via a quasi-3D refined theory," Composite Structures, vol. 220, pp. 289-303, 2019.

[34] N. V. Nguyen, H. Nguyen-Xuan, D. Lee, and J. Lee, “A novel computational approach to functionally graded porous plates with graphene platelets reinforcement," Thin-Walled Structures, vol. 150, Article ID 106684, 2020.

[35] N. V. Nguyen, J. Lee, and H. Nguyen-Xuan, "Active vibration control of GPLs-reinforced FG metal foam plates with piezoelectric sensor and actuator layers," Composites Part B: Engineering, vol. 172, pp. 769-784, 2019.

[36] T. T. Tran, Q. H. Pham, and T. Nguyen-Thoi, "Static and free vibration analyses of functionally graded porous variablethickness plates using an edge-based smoothed finite element method," Defence Technology, 2020.

[37] L. Lurlaro, M. Gherlone, M. D. Sciuva, and M. Sorrenti, "Bending and free vibration analysis of functionally graded sandwich plates using the refined zigzag theory," Journal of Sandwich Structures and Materials, vol. 16, pp. 669-699, 2014.

[38] P.-S. Lee and K.-J. Bathe, "Development of MITC isotropic triangular shell finite elements," Computers \& Structures, vol. 82, no. 11-12, pp. 945-962, 2004.

[39] G. R. Liu, T. Nguyen-Thoi, and K. Y. Lam, "An edge-based smoothed finite element method (ES-FEM) for static, free and forced vibration analyses of solids," Journal of Sound and Vibration, vol. 320, no. 4-5, pp. 1100-1130, 2009.

[40] H. Nguyen-Xuan, G. R. Liu, T. Nguyen-Thoi, and C. NguyenTran, "An edge-based smoothed finite element method (ESFEM) for analysis of two-dimensional piezoelectric structures," Smart Materials and Structures, vol. 18, no. 6, Article ID 065015, 2009.

[41] T. Nguyen-Thoi, G. R. Liu, H. C. Vu-Do, and H. NguyenXuan, "An edge-based smoothed finite element method for visco-elastoplastic analyses of $2 \mathrm{D}$ solids using triangular mesh," Computational Mechanics, vol. 45, no. 1, pp. 23-44, 2009.

[42] T. N. Thanh, G. R. Liu, H. Nguyen-Xuan, and T. NguyenThoi, "An edge-based smoothed finite element method for primal-dual shakedown analysis of structures," International Journal for Numerical Methods in Engineering, vol. 82, no. 7, pp. 917-938, 2010.

[43] T. Nguyen-Thoi, G. R. Liu, and H. Nguyen-Xuan, "An n-sided polygonal edge-based smoothed finite element method (nESFEM) for solid mechanics," International Journal for $\mathrm{Nu}$ merical Methods in Biomedical Engineering, vol. 27, no. 9, pp. 1446-1472, 2010.

[44] G. R. Liu and T. T. Nguyen, Smoothed Finite Element Methods, CRC Press, Taylor and Francis Group, New York, NY, USA, 2010.

[45] T. Chau-Dinh, Q. Nguyen-Duy, and H. Nguyen-Xuan, "Improvement on MITC3 plate finite element using edgebased strain smoothing enhancement for plate analysis," Acta Mechanica, vol. 228, no. 6, pp. 2141-2163, 2017.

[46] T.-K. Nguyen, V.-H. Nguyen, T. Chau-Dinh, T. P. Vo, and H. Nguyen-Xuan, "Static and vibration analysis of isotropic and functionally graded sandwich plates using an edge-based MITC3 finite elements," Composites Part B: Engineering, vol. 107, pp. 162-173, 2016.

[47] Q.-H. Pham, T.-V. Tran, T.-D. Pham, and D.-H. Phan, "An edge-based smoothed MITC3 (ES-MITC3) shell finite element in laminated composite shell structures analysis," International Journal of Computational Methods, vol. 15, no. 7, Article ID 1850060, 2017.

[48] Q.-H. Pham, T.-D. Pham, V. T. Quoc, and D.-H. Phan, "Geometrically nonlinear analysis of functionally graded shells using an edge-based smoothed MITC3 (ES-MITC3) finite elements," Engineering with Computers, vol. 36, no. 3, pp. 1069-1082, 2019.

[49] T. D. Pham, Q. H. Pham, V. D. Phan, H. N. Nguyen, and V. T. Do, "Free vibration analysis of functionally graded shells using an edge-based smoothed finite element method," Symmetry, vol. 11, no. 5, p. 684, 2019.

[50] D. Pham-Tien, H. Pham-Quoc, T. Vu-Khac, and N. NguyenVan, "Transient analysis of laminated composite shells using an edge-based smoothed finite element method," in Proceedings of the International Conference on Advances in Computational Mechanics, pp. 1075-1094, Springer, Singapore, February 2018.

[51] K.-U. Bletzinger, M. Bischoff, and E. Ramm, "A unified approach for shear-locking-free triangular and rectangular shell finite elements," Computers \& Structures, vol. 75, no. 3, pp. 321-334, 2000.

[52] T. Nguyen-Thoi, P. Phung-Van, H. Nguyen-Xuan, and C. Thai-Hoang, "A cell-based smoothed discrete shear gap method using triangular elements for static and free vibration analyses of Reissner-Mindlin plates," International Journal for Numerical Methods in Engineering, vol. 91, no. 7, pp. 705-741, 2012.

[53] K.-J. Bathe and E. N. Dvorkin, "A formulation of general shell elements-the use of mixed interpolation of tensorial components," International Journal for Numerical Methods in Engineering, vol. 22, no. 3, pp. 697-722, 1986.

[54] T. T. Tran, V. K. Tran, P. B. Le, V. M. Phung, V. T. Do, and H. N. Nguyen, "Forced vibration analysis of laminated composite shells reinforced with graphene nanoplatelets using finite element method," Advances in Civil Engineering, vol. 2020, Article ID 1471037, 17 pages, 2020. 